\title{
Los Pasadizos Elevados entre la Mezquita y el Alcázar Omeya de Córdoba. Estudio arqueológico de los sābāțăt $t^{1}$
}

\section{The Elevated Passageways between the Mosque and the Umayyad Alcazar of Córdoba. Archaeological study of the sābātāt}

\author{
Guadalupe Pizarro Berengena \\ Arqueóloga GMU-UCO
}

En memoria de Juan Souto, a quien conocí junto a los sābātạt

\section{RESUMEN}

Entre todos los edificios que construyeron los musulmanes en la capital de al-Andalus uno de los que más han despertado el interés de la comunidad científica y de los propios cordobeses han sido los pasadizos elevados, en árabe sābățăt, que desde el siglo IX unieron la antigua Mezquita Mayor de la capital con el alcázar andalusí. Las recientes obras de infraestructura de la c/ Torrijos han sacado a la luz los cimientos de estos sābāta ât sobre los que tanto se ha especulado y que paradójicamente apenas se encontraban a escasos centímetros bajo el adoquinado de la calle actual.

\section{SUMMARY}

Among the constructions the Muslims built in the capital of al-Andalus that have raised the most interest amongst both the scientific community and the inhabitants of Cordoba are the elevated passageways, called sābātatat Arabic, connected the Mosque to the Alcazar from the 9th century on. The recent renovation of Torrijos Street has uncovered the foundations of these sābattāt, ironically just a few centimetres underneath the present cobbled street.

PALABRAS CLAVES: $s \bar{a} b \bar{a} t$, corredor, qibla, califa, ampliación, Madīnat al-Zahrā'.

KEY WORDS: sābāt, corridor, caliph, extension, Madīnat al-Zahrā'.

A pesar de lo que se cree popularmente, los sābātāt fueron los pasadizos utilizados por los emires y los califas cordobeses para acceder desde el alcázar has-

\footnotetext{
${ }^{1}$ Este trabajo se ha realizado en el Convenio de Colaboración que los miembros del Área de Arqueología de la Universidad de Córdoba, mantiene con la Gerencia Municipal de Urbanismo del Ayuntamiento de Córdoba para el estudio de Córdoba, ciudad histórica, entendida como yacimiento único (www.arqueocordoba.com). La planimetría es un trabajo de F. R. Sánchez y M. A. Carmona, miembros del mismo equipo.
}

ta la cercana mezquita sin salir a la calle (Fig. 1). Constaban de dos partes: la exterior, que unía ambos edificios, se asemejaba a un puente de uno o varios arcos sobre el que se discurría el pasadizo propiamente dicho, sin que el tránsito por la calle se viese interrumpido. En el interior de la mezquita, el sābāt permitía al soberano llegar hasta la maqșūra sin ser visto por los fieles que se encontraban en el interior ${ }^{2}$.

\section{EL $S \bar{A} B \bar{A} T$ EMIRAL}

Al morir el emir 'Abd al-Rahmmān II en el año 852 la primera ampliación de la mezquita prácticamente había concluido, a excepción de algunos detalles que ultimaron sus sucesores. Entre los años 864-865, Muhammad I construyó la maqsūra y la Puerta de los Visires, hoy conocida como Puerta de San Sebastián, mientras que la construcción de la sala del tesoro o Bayt al-Māl se atribuye al emir al-Mundir (886-888); más tarde, fue el emir 'Abd Allāh (888-912) quien mandó edificar el pasadizo que unió el alcázar, sede del poder político, y la mezquita aljama de la capital cordobesa (Ocaña 1942; 1979: 279-280).

La muerte del emir 'Abd al-Raḥmān II y la conclusión de una de sus obras más importantes pusieron fin a una etapa próspera económica, política y culturalmente. Cuando el nuevo emir 'Abd Allāh (888-912) decidió la construcción del primer sābāt las circunstancias ya habían cambiado notablemente: tuvo que

${ }^{2}$ Acerca de los sābātạt domésticos, resultado del proceso de transformación urbana en la ciudad islámica, ver la obra de García Bellido y García de Diego (2000: 259-260). 


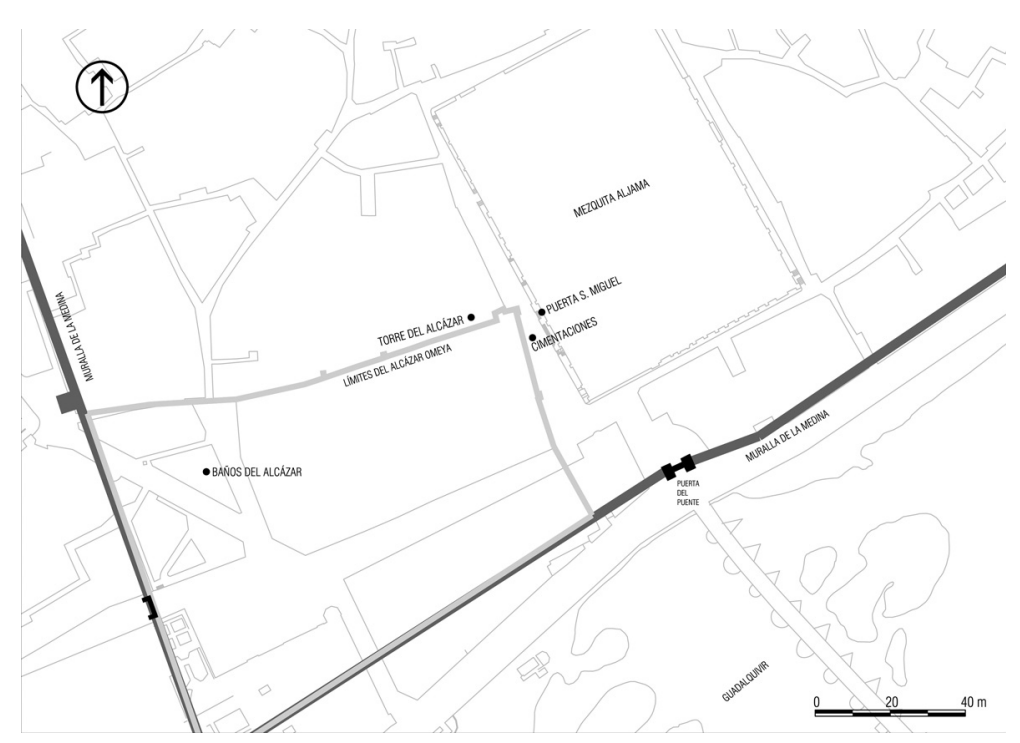

Figura 1. Límites del alcázar Omeya y la mezquita aljama de Córdoba sobre el parcelario actual. Situación de las sólidas cimentaciones halladas al sur de la Puerta de S. Miguel.

hacer frente a distintos movimientos de independencia regional y fueron pocas las edificaciones importantes promovidas durante su mandato a excepción del pasadizo que nos ocupa (Lévi Provençal 1950: 888-912).

Ibn Hayyān (987-1075) en al-Muqtabis explica las razones que llevaron al emir a ordenar su edificación:

"Entraba por la puerta del Oeste, la primera entre todas, conocida por 'la Puerta de los Ministros' 3 . Al verlo los fieles se ponían de pie hasta que entraba en su cámara particular, actitud que disgustaba a los devotos ortodoxos. Por entonces le escribió el faquí Sa'id ben Jamir, diciéndole: 'Os haga Dios un digno y piadoso fiel, Señor Imam. Los hombres deben ponerse de pie solamente ante Dios, el Creador del mundo; sin embargo, ante ti se levantan apenas te ven llegar. ¡Oh, no! Tú no deberás aceptar ni dar a tu pueblo más que la verdad; pues solo la verdad te hará llegar a la presencia de Dios. El poder es patrimonio de Dios, que no tiene igual; y quien se humille a los designios de Dios, Dios lo elevará. La advertencia es útil a los fieles, y solo la recuerda el que se arrepiente'.

Desde entonces ordenó el Emir a los que acudían a la ceremonia religiosa, que no se levantaran cuando lo vieran llegar o irse, sino que permanecieran sentados en sus puestos. Mas la orden del Emir sólo fue aceptada por una minoría. Entonces mandó construir el corredor subterráneo, conocido por al-Sābāt, cuya bóveda se veía aflorar por la calle, entre el Palacio del Emir y la Mezquita. Dicho corredor comunicaba el

${ }^{3}$ Esta es la puerta por la que los emires hacían su entrada en la sala de oración, al menos desde el mandato de Muhammad I (Gómez Moreno 1951: 58). alcázar con su oratorio particular en la Gran Mezquita. Por él entraba el Emir sin ser visto, cuando acudía a la oración en compañía de su comitiva, formada por los cortesanos, los eunucos y los criados. Allí, en el oratorio privado, después de cumplir con sus deberes piadosos permanecía en tertulia, platicando con sus ilustres acompañantes. De este modo nadie le veía, ni a su ida ni a su retorno, evitaba que el público se pusiera de pie cuando se hacía presente, y evitaba también la permanente vigilancia de su persona durante el trayecto. Fue el primero de los califas Umayya que en Andalucía adoptó esa costumbre. Todos los que sucedieron imitaron su ejemplo".

(....)

"Fue el primero que abrió una puerta en su palacio para comunicar con la mezquita, desde la muralla al Sur, contigua al templo, uniendo a ambos - alcázar y mezquita - con su sābāț; esto es un corredor abovedado construido con gruesas piedras que se encuentran bajo el amplio camino que conduce a la Puerta de la Alcántara, otra de las Puertas de la ciudad. Unió dicha puerta con su cámara privada en la mezquita. A ella acudía desde su alcázar sin ser visto por nadie, acompañado por su séquito y servidumbre. También asistía a los oficios ceremoniales en algunos día de la semana" (Ibn Hayyān 1951: 157-158) .

\footnotetext{
${ }^{4}$ Ibn 'Idārī, al hacer recuento de las obras del 'Abd Allāh en la capital del emirato también describió el pasadizo emiral, aunque no incluyó tantos detalles en su relato “(...) y fue el que edificó el cobertizo entre el alcázar y la alhama en Medina Cortoba, deseando dar testificación de la solemnidad del giuma. (...) Sentábase en el cobertizo antes de la oración del giuma, y después de ella, y veía a las gentes, dejándose
} 
Efectivamente, el estudio de los fustes y capiteles de acarreo utilizados en la mezquita de 'Abd alRaḥmān II ha concluido que su distribución en el edificio no es arbitraria o casual. Al contrario, las columnas destacan el recorrido seguido por el emir a lo largo de la nave central, así como los espacios más importantes de la sala de oración: la qibla y la antesala del mihrab (Cressier 1984, 1985; Juez 2003; Peña 2010). Debemos imaginar cuál sería el impacto causado por la entrada de 'Abd Allāh y su séquito en la mezquita, desde la Puerta de los Visires hasta la maqșūra. La expectación y el revuelo que provocaba entre los fieles que se encontraban orando solo terminaría con la construcción del sābāt. El pasadizo, por tanto, solo pudo ser un añadido al edificio original ${ }^{5}$.

Hasta ahora diferentes teorías coincidían en señalar que la puerta que unía el pasadizo emiral con la mezquita era la de San Miguel (Fig. 1 y 2). Las reducidas dimensiones del vano, la decoración de la puerta, pobre en comparación con las restantes entradas de la aljama, y las evidentes reformas que presenta el testero al que se abre refuerzan dicha interpretación. Lo mismo ocurre con el hecho de que la puerta de San Miguel sea asimétrica al exterior, un ligero descentramiento utilizado para dar acceso directo a uno de los intercolumnios de la sala de oración (cfr. Marfil 2010: 120-130, 319). Diferentes autores han elaborado varias hipótesis sobre el aspecto que pudo presentar

notar como partícipe de sus conversaciones y afectos, y se regocijaba en sus sociedades, y oía el dicho del quejoso, sin que nada pudiera ocultársele de cuanto ocurría a las gentes (..) edificó el cobertizo del alcázar hasta la aljama, para frecuentarla en las azalas, y comunicar la azala de la multitud a un lado del almimbar, ejercitándose con celo hasta que le llamó su señor..." (Ibn 'Iḍ̄āī 1993: 192-193).

${ }^{5}$ La intervención de 'Abd Allāh en el interior de la mezquita se limitó a la construcción del sābāṭ. No culminó ninguna de las obras iniciadas por sus antecesores (Torres Balbás 1965: 415-416).
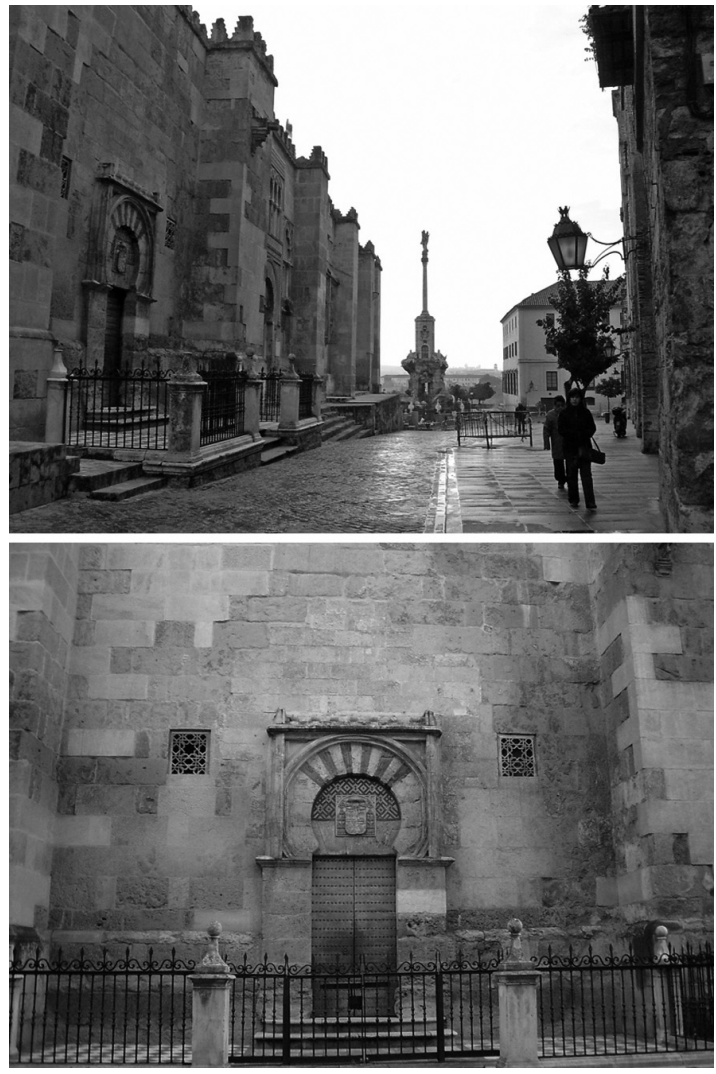

Figura 2. Puerta de S. Miguel. Vista general en la calle Torrijos $\mathrm{y}$ vista frontal desde el exterior.

el pasadizo emiral, la más conocida, la de L. Golvin (1979), por incluir una restitución en alzado de su parte externa (Fig. 3). En cuanto a su parte interna, L. Torres Balbás, pensó que la conexión del sābāt con la maqșūra se haría mediante una sitara, es decir, un cerramiento de madera tallada que atravesaría la sala de oración (Torres Balbás 1965: 415-416).

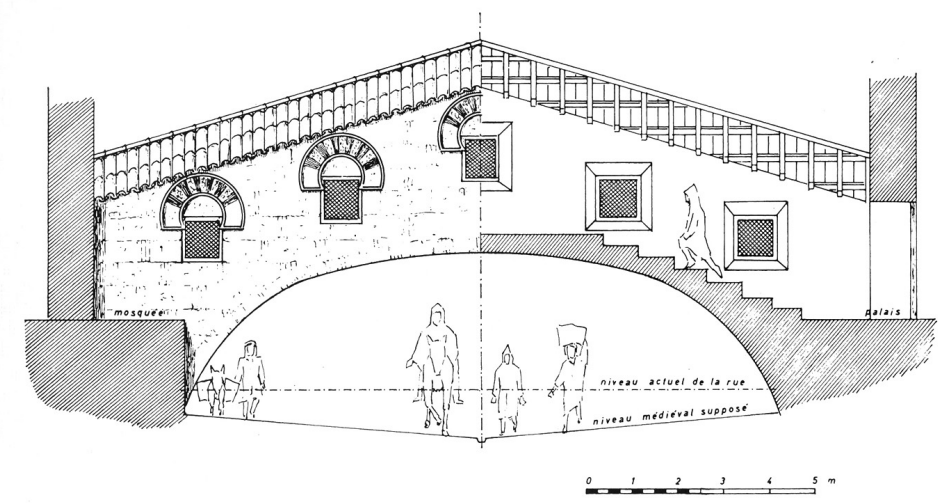

Figura 3. Reconstrucción del alzado del pasadizo de ‘Abd Allāh según L. Golvin (1979). 

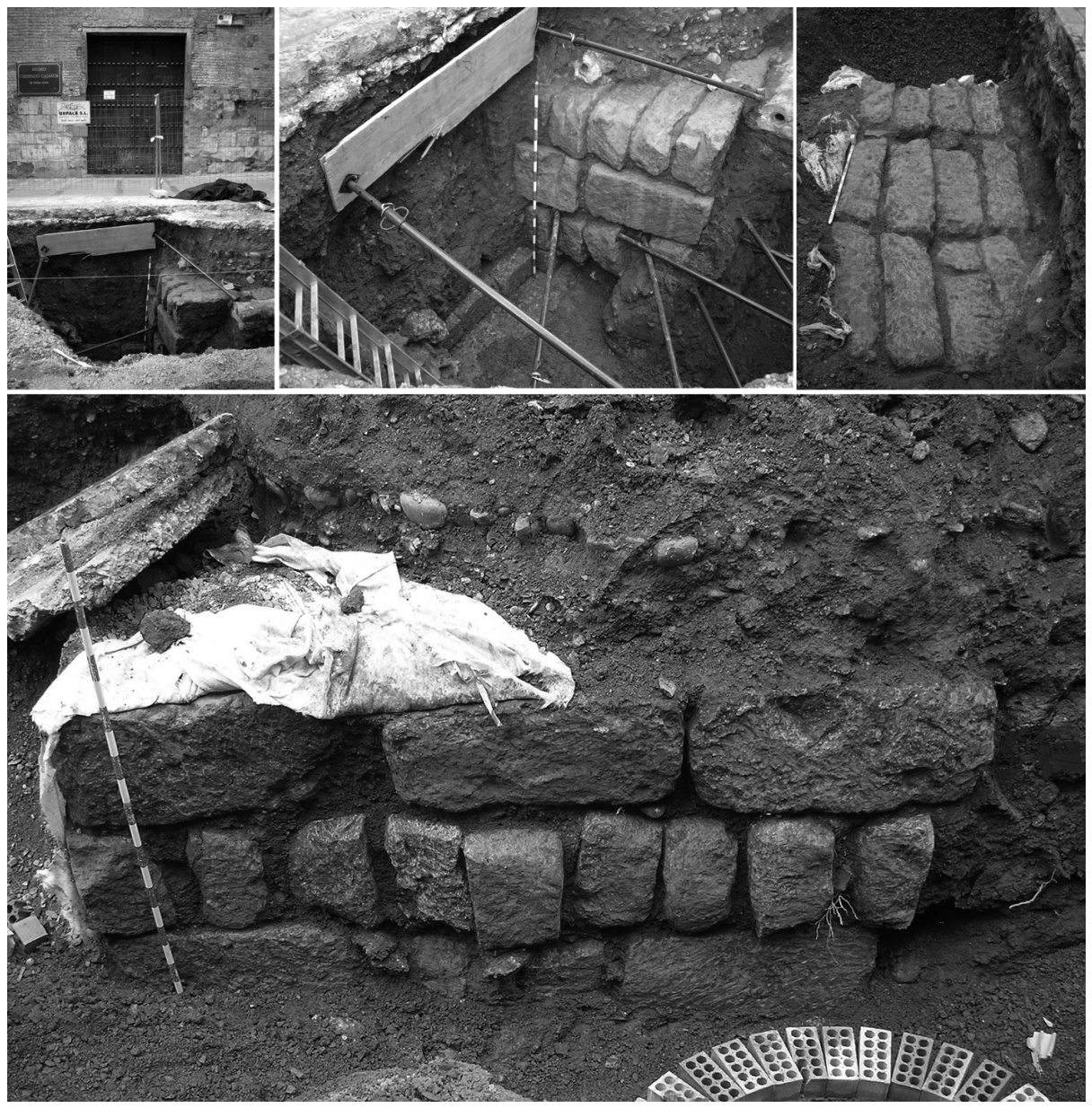

Figura 4. Vista de las cimentaciónes halladas en la c/ Torrijos junto a la actual puerta del Museo Diocesano.

Sin embargo, durante nuestra intervención, a la sorprendente ausencia de estructuras de interés arqueológico frente a la Puerta de San Miguel se unió la aparición de una cimentación de gran entidad unos metros al sureste de la ubicación que se presuponía para el sābāt de 'Abd Allāh. Está, situada junto a la Puerta del Espíritu Santo de la Catedral, consistía en un bloque macizo de grandes tizones de calcarenita (1 x $0,38 \times 0,52 \mathrm{~m}$ ) superpuestos en hiladas de orientación perpendicular unas con otras. Se documentó en un tramo de 3,25 m de longitud (Noroeste-Sureste), aunque debió ser mayor, pues se prolongaba hacia una zona donde no intervinimos por no estar afectada por la reforma de la calle. Su anchura mínima era de $1,40 \mathrm{~m}$ en sentido Noreste-Suroeste, equivalente a un mínimo de cinco hileras de tizones, y medía $1,50 \mathrm{~m}$ de alzado. Su superficie se encontró a la cota 102,23 m.s.n.m. (Fig. 4).

Las cimentaciones realizadas exclusivamente con tizones fueron habituales en época islámica: nos remitimos a las excavaciones que han sacado a la luz los cimientos de la ampliación de la mezquita de Almanzor (Marfil 2003). Un término comparativo oportuno es la cimentación del alminar que construyó Hišām I para la aljama, también emiral, aunque casi un siglo más antiguo que el sābāt de 'Abd Allāh. F. Hernández apuntó que: "los (sillares) del alminar de Hixam, como destinados a cimientos, se dejaron en bruto para las indispensables creces para la labra, y mientras en las tres hiladas inferiores se colocaron a hueso, en la superior se cogieron con un mortero en que la cal predomina sobre la arena y es de coloración algo agrisada" " (Hernández 1975: 131) (Fig. 5).

\footnotetext{
${ }^{6} \mathrm{El}$ alminar estaba compuesto por hiladas de sillares cuyas potencias oscilaban entre 0,51 y $0,59 \mathrm{~m}$. La longitud de los sillares del alminar es de $1,20 \mathrm{~m}$ en las hiladas inferiores, tendiendo a aminorar en las más altas donde llega a limitarse a los 1,14 m (Hernández 1975: 131). Están dispuestos a soga y tizón en proporción 1 - 1 casi perfecta en determinados puntos de su alzado (segunda y tercera hilada de sillares del lateral oeste de su cimentación). No obstante, en su base también existen hileras hechas casi exclusivamente de tizones.
} 

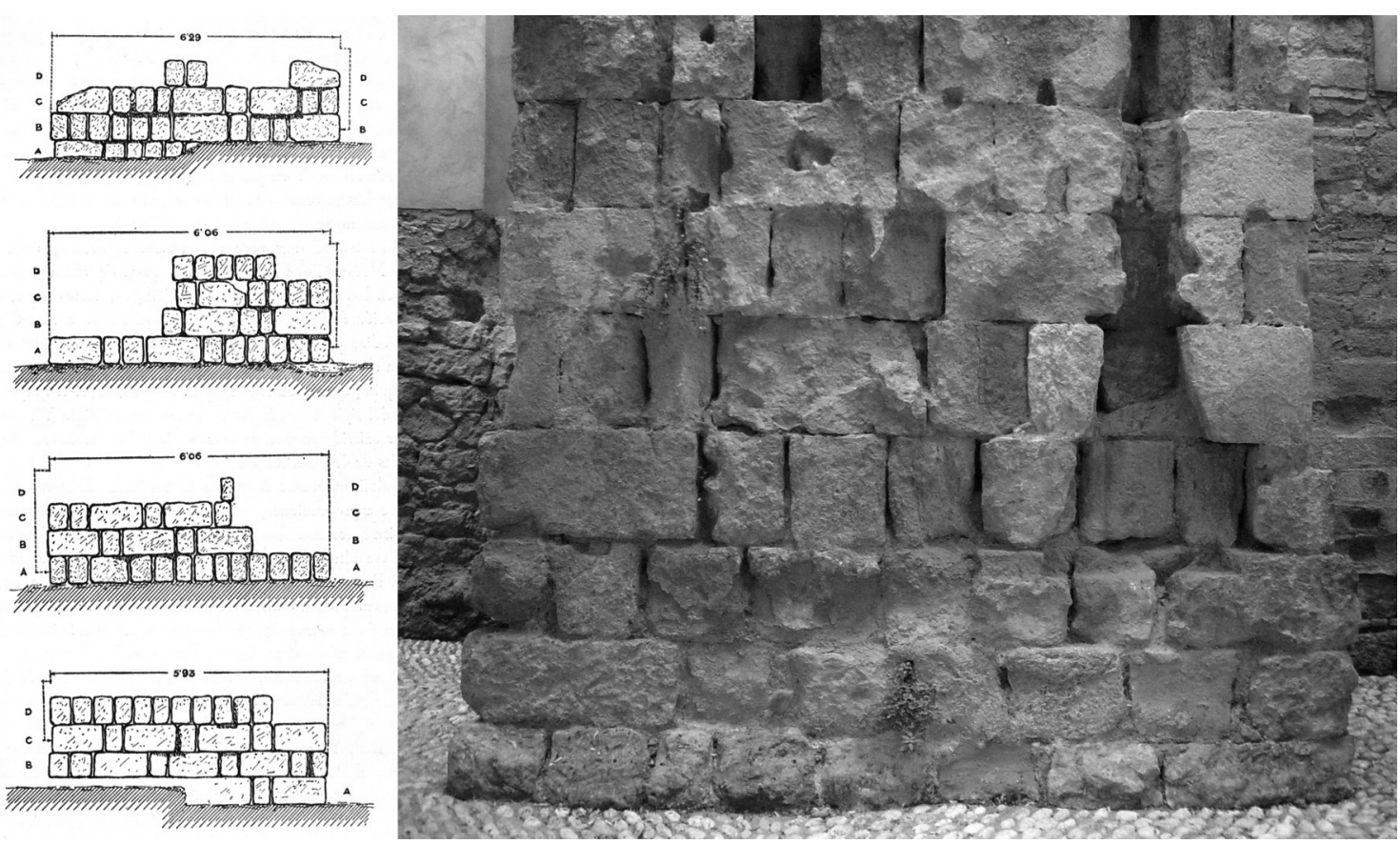

Figura 5. A la izquierda, alzados del alminar mandado construir por Hišām I en la mezquita de Córdoba según F. Hernández (1975: Fig. 26). A la derecha, una de las torres del alcázar andalusí conservada en el Palacio de Congresos de Córdoba.

Dicho esto, y sabiendo que la Puerta de San Miguel, a día de hoy, se confirma como nexo de unión entre el sābāt de 'Abd Allāh y la aljama, nos preguntamos si las cimentaciones halladas por nosotros apenas a un metro de profundidad podrían relacionarse con el pasadizo emiral, ello a pesar de su sorprendente ubicación (Fig. 1).

En este sentido, nos remitimos a los estudios de F. Hernández, B. Pavón y A. Vallejo sobre la mezquita de al-Zahrā', fundada en 941-945 (Fig. 6) (Pavón 1966: 23-24; Vallejo 2010: 197-209). Dicho edificio se halló muy arrasado, a nivel de cimientos; no obstante, los autores mencionados coinciden en que se erigió en dos fases constructivas distintas. Por una parte se debería considerar una mezquita primitiva de qibla y mih̆rāb únicos, y por otra, un añadido de fecha posterior, esto es, una segunda qibla o trasqibla que guarda notables diferencias constructivas respecto al resto del edificio. Originalmente, el califa y su comitiva accederían a la mezquita de al-Zahrā' a través de un pasadizo adosado al lado oriental del jardín alto. Posteriormente, con motivo de la reestructuración del palacio, se construiría la mencionada trasqibla, generándose así un corredor en la parte posterior de la aljama. Necesariamente hubo

\footnotetext{
Muy cerca de la mezquita, en el interior del actual Palacio de Congresos de Córdoba, también se conserva una de las torres del antiguo alcázar andalusí, donde se aprecia una técnica edilicia muy similar a la de la estructura que hemos documentado nosotros (Fig. 5).
}

que levantar también un puente de tres ojos para salvar el fuerte desnivel existente entre ambos elementos, corredor y pasadizo (Vallejo 2010: 201-204).

Si el sābāt de la aljama cordobesa se hubiese ubicado al sureste de la Puerta de San Miguel habría tenido una imagen ligeramente más esbelta que la que se ha propuesto hasta ahora. La altura total del edificio de 'Abd Allāh habría sido de unos diez metros, a contar por encima de los 102,20 m.s.n.m. a la que hallamos los cimientos descritos ${ }^{7}$. Además, en este punto la calle es ligeramente más ancha, $14,95 \mathrm{~m}$, por lo que el pasadizo podría sustentarse bien sobre un solo arco, bien sobre varios arcos tal y como propuso Marçais al interpretar la frase "ma'qoûdàn 'ala hanàiâ" en el sentido de que pasadizo tenía una bóveda sobre arcos fajones" $"$.

Es posible que la puerta del Museo Diocesano, abierta en la fachada oriental del antiguo alcázar omeya, sea heredera del vano por el que se accedía desde la fortaleza al sābāt. De hecho, otros investigadores ya han apuntado la localización de una puerta conocida

\footnotetext{
${ }^{7}$ La altura del machón que separa las ampliaciones de la mezquita de 'Abd al-Rahmän II y al-Hakam II, al Sur de la Puerta de San Miguel, es de 13,84 m. La altura del sābāt emiral debió determinarla la fachada del alcázar omeya (vide infra).

8 "Quant au passage lui-même sâbât, Ibn I'Adharî nous dit qu'il comportait une voûte reposant sur des arcs dobleaux, sàbâtan ma'qoûdàn 'ala hanàîâ' (Marçais 1929: 220).
} 


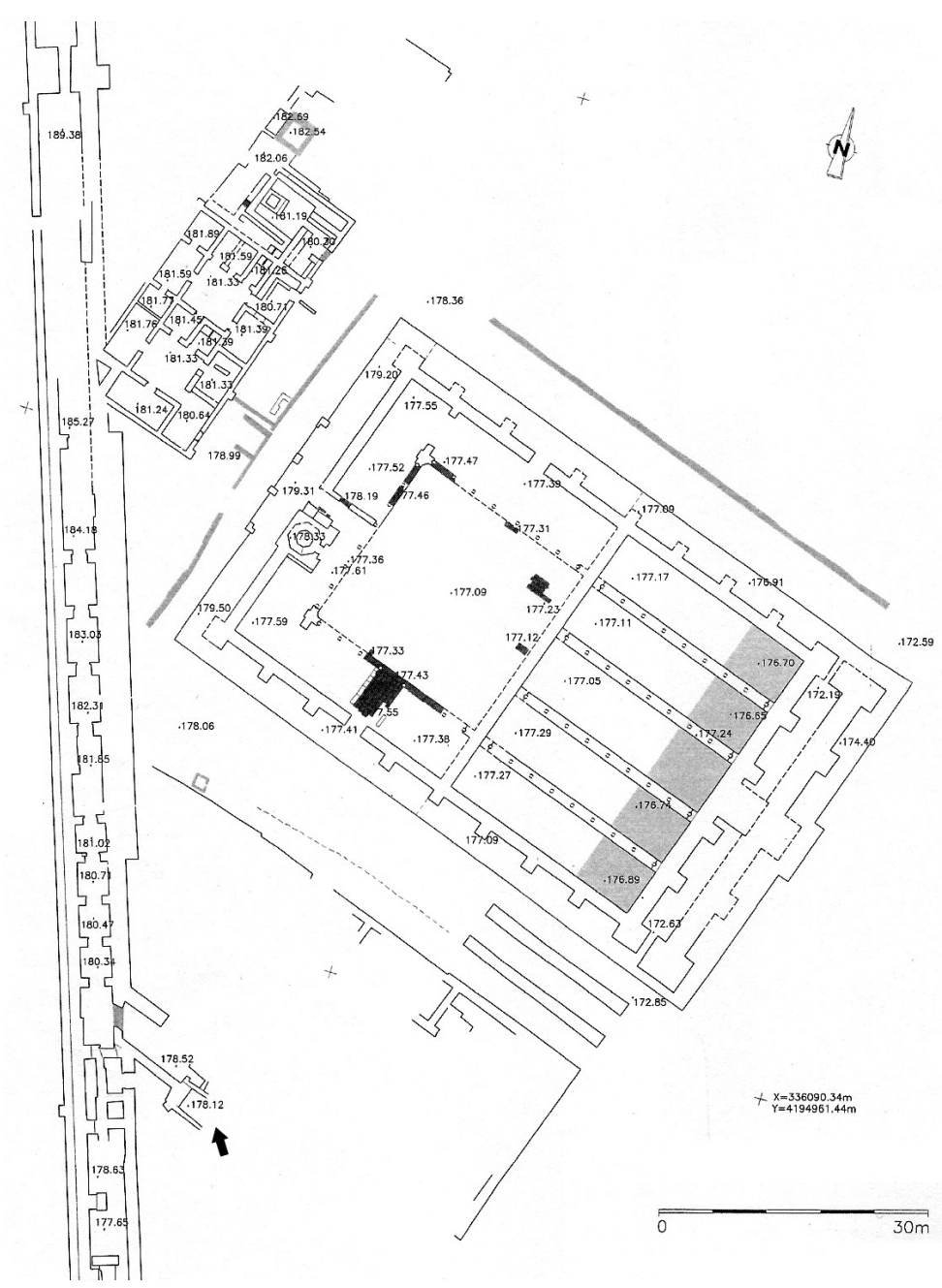

Figura 6. Planta de la mezquita de Madinat al-Zahrā' (a partir de Vallejo 2010: Fig. 14). Obsérvese, al Este, el pasadizo procedente de la zona regia, dividido en estancias rectangulares. Los restos del puente de tres ojos se han marcado con una flecha.

en las fuentes como "Puerta de la Mezquita Aljama"9 o del "sābāṭ" en el extremo norte del muro oriental del alcázar andalusí, la cual habría quedado abierta tras el derribo del pasadizo ${ }^{10}$ (Figs. 1 y 4 ).

\footnotetext{
9 “... la cuarta puerta es la llamada Puerta de la Mezquita, que es una entrada antigua utilizada por los califas para entrar los viernes en mezquita a través de un pasadizo" (Rubiera 1988: 122-123).

En cambio carecemos de referencias escritas sobre la permanencia en la mezquita de una antigua puerta que, después del derribo del sābāt, conectara la aljama con el alcázar andalusí.

10 'Abd-Allāh también construyó una de las puertas del alcázar llamada Puerta de la Justicia o Bab al-'Adl. Casi todos los autores consultados coinciden en que dicha puerta estaría abierta en el lienzo meridional del alcázar. No obstante, la puerta que comunicaba la fortaleza con el sābāt, pudo quedar abierta tras el derribo del pasadizo, recibiendo por ello tres denominaciones distintas a lo largo del tiempo, "puerta
}

Las cimentaciones halladas por nosotros, por su ubicación inesperada, son de difícil interpretación. Se trata de la única estructura aparecida hasta el momento lo suficientemente fuerte como para sostener un recio edificio, y desde el punto de vista funcional parece lógico pensar en la existencia de una doble qibla tras la ampliación emiral. Con todo, plantear la construcción un pasadizo similar al de Madinnat al-Zahrā' en la parte posterior de la mezquita de 'Abd al-Raḥmān II es una hipótesis más que arriesgada: no hemos podido confirmar si el andén que rodea la mezquita esconde los cimientos de un pilar similar al que hemos encontrado $\mathrm{y}$, aunque el mihrab de ' $A b d$

del sābāt", "puerta de la mezquita" y "puerta de la justicia" (Torres Balbás 1965: 593; Castelló 1976: 131; Montejo y Garriguet 1998: 305; Montejo et alii 1999: 167; Vallejo 2010: 202 , nota 84 ). 
al-Raḥmān II sí ha sido excavado, no se han hallado indicios de un posible corredor adosado a su parte externa (Fernández 2009a: 108; 2009b: 88-92) ${ }^{11}$.

No nos queda, pues, más que revisar el texto del Muqtabis de forma crítica, pues no es lógico describir el sābāt de Abd-Allāh como un corredor subterráneo. Solo cabe suponer que cuando Ibn Hayyān redactaba su obra, el pasadizo emiral ya se había derribado, por lo que sus cimientos estarían soterrados bajo el "amplio camino que conducía a la Puerta de la Alcántara” (Puerta del Puente). El mismo autor escribió que " 'Abd-Allāh abrió una puerta en su palacio para comunicar con la mezquita, desde la muralla al Sur, contigua al templo, uniendo a ambos - alcázar y mezquita- con su Sābāṭ”. Esta descripción se ajusta a los sābātāt que estaban en pie en tiempos de Ibn Hayyān (el de al-Zahrā' y el de al-Hakam II), y el autor la hizo extensible a un edificio que se había demolido 20 años antes de su nacimiento. Ahora bien, de ser así, la Arqueología tiene aún dos tareas pendientes: encontrar los fundamentos del sābāt emiral más allá de la Puerta de San Miguel e interpretar las gruesas cimentaciones aparecidas en la c/ Torrijos en 2007.

En otro orden de cosas, el Muqtabis indica claramente que las razones para levantar el sābāt cordobés fueron de índole religiosa. Sin embargo, el mismo texto añade que 'Abd Allāh, al no ser visto cuando acudía a la oración, "evitaba también la permanente vigilancia de su persona durante el trayecto"(vide supra). Las cuestiones de seguridad fueron esenciales en un reinado turbulento como el suyo: no olvidemos que el emir escuchaba y vigilaba a sus súbditos desde el pasadizo, al parecer, sin ser visto (Vallejo 2010: 202) ${ }^{12}$.

Con todo, otros autores piensan que la comunicación física y simbólica entre mezquita y alcázar marcaría aún más el carácter islámico del poder, así como se legitimaba a los Omeyas como soberanos islámicos (Juez 2003: 122 y 183). F. Valdés apunta que hasta la construcción del sābāt de 'Abd Allāh, el emir quedaba igualado con el resto de sus súbditos en el plano espiritual al realizar con ellos la preceptiva oración de los viernes en la aljama; la separación física del resto de los fieles constituiría "un paso más hacia la restauración del califato" (Valdés 1988: 566).

La existencia de una conexión física entre el alcázar y la mezquita principal de la ciudad no es exclusiva de Córdoba: en palabras de Torres Balbás el sābāt construido por 'Abd Allāh renovaba una tradición oriental preexistente (Torres Balbás 1957: 415-416), mientras que Félix Hernández veía un claro precedente del pa-

\footnotetext{
${ }^{11}$ Véase también la estructura descrita en la p. 114 de la referencia mencionada (Fernández 2009a).

${ }^{12}$ Vide supra nota 4.
}

sadizo de Madīnat al-Zahrā’ en el palacio de Jirbat alMafyar (segundo cuarto del s. VIII) (Hernández 1975). Otros autores se han ocupado del estudio de sābātāt orientales y africanos ${ }^{13}$, algunos anteriores al primer edificio cordobés; otros posteriores a él en el tiempo. Lo que nos interesa, llegados a este punto, es que en Córdoba la unión física los edificios que constituían el núcleo la ciudad islámica dio lugar a una tipología arquitectónica, una construcción que materializaba la unión del poder político y poder religioso encarnados en la persona del emir. Su aparición tuvo lugar cuando las circunstancias la hicieron especialmente oportuna, más aún, necesaria, y estaba además perfectamente avalada por la tradición arquitectónica oriental. Por eso, aun cuando " 'Abd Allāh fue el primero de los califas Umayya que en Andalucía adoptó esa costumbre. Todos los que sucedieron imitaron su ejemplo" (Ibn Hayyān 1951: 157-158).

\section{EL $S \bar{A} B \bar{A} T$ CALIFAL}

La ampliación de la aljama de Córdoba hacia el Sureste por parte del califa al-Hakam II (961-976) obligó a que el sābāt de 'Abd Allāh, construido casi un siglo antes, fuese derribado. Este fue sustituido por un pasadizo de nueva construcción que unió la maqșūra, en su nuevo emplazamiento, con el extremo meridional del alcázar. Los dos sābātāt no convivieron en el tiempo sino que se sucedieron a lo largo de los siglos; ambos marcaron la imagen de la ciudad

\footnotetext{
${ }^{13}$ En los orígenes del Islam, la mezquita era escenario de actividades y funciones que posteriormente pasaron a celebrarse en otro tipo de edificios (Ettinghausen-Grabar 1987. 43; Epalza 1999: 100). La proximidad entre el palacio del soberano y las mezquitas principales fue habitual en las medinas islámicas medievales. Uno de los ejemplos más antiguos lo tenemos en la ciudad de Kufa, donde el Palacio del Gobernador estaba adosado a la cabecera de la mezquita de la capital en una fecha temprana, 670. De este modo se pretendía evitar un nuevo robo del tesoro que se custodiaba en la residencia de la autoridad (Kuban 1994: 80; Juez 2003: 121-123). También estuvieron próximos el palacio y la mezquita de Damasco, antigua capital de los Omeyas, de cuya aljama principal era un reflejo la de Córdoba. De sus cuatro entradas, una a cada lado del edificio, la meridional consistía en un triple vano reservado al acceso del califa desde su palacio hasta la nave central del edificio (Marçais 1929: 222; Ettinghausen y Grabar 2000: 45; Juez 2003: 183). La capital abbasí, Bagdad (762), fue concebida en torno a mezquita y palacio, situados en el centro geográfico de la ciudad, si bien, en ese caso, los dos edificios estaban separados por una explanada (Ettinghausen y Grabar 1987: 85). Juez ha señalado que, en los casos en que el palacio estaba alejado de la aljama, el soberano ordenaba erigir pequeños edificios comunicados directamente con el oratorio, caso de las mezquitas egipcias de Ibn Tulun (terminada en 879) y Abu Dulaf (847) (Juez 2006: 122-184). Acerca de otros precedentes de los pasadizos cordobeses, véase la tesis doctoral recientemente leída por P. Marfil (2010).
} 
mientras permanecieron en pie al cruzarse a modo de puentes sobre una de sus calles más importantes ${ }^{14}$. Fue al-Hakam II quien convirtió el sābāt en parte del lenguaje de un nuevo régimen político, el califato, en el que el califa está definitivamente separado de sus súbditos en el plano espiritual y su poder perfectamente legitimizado en la mezquita. En su ampliación de la aljama, al-Hakam II mostró respeto por la obra de sus antecesores dinásticos manteniendo incluso la orientación poco ortodoxa de la qibla. En consecuencia, también era obligado construir un nuevo sābāt con el que se mantuviera el acceso directo del califa a una nueva maqșüra. Mientras que la mezquita de 'Abd al-Raḥmān II fue el referente para el sābāt de alZahrā', las soluciones adoptadas en este último fueron el modelo del pasadizo califal (Vallejo 2010: 200).

La monumentalidad del pasadizo de al-Hakam II estuvo en parte determinada por su ubicación en un punto donde la calle es mucho más ancha, teniendo la cota de suelo mucho más baja que la de la sala de oración. Gracias a su solidez permaneció en pie hasta bien entrado el s. XVII, por eso son numerosas las fuentes documentales que lo describen. M. Nieto, en sus monografías sobre la mezquita-catedral hace una recopilación de todas ellas:

Un primer testimonio directo son los propios mosaicos de las puertas laterales de la ampliación de al-Hakam II: "Ha ordenado al Imam al-Mustansir bi-llah, siervo de Allāh, al-Hakam, Emir de los Creyentes -que Allāh le favorezca- a su liberto y $h \bar{a} \bar{y} \hat{i} i b$ $\hat{Y} \mathrm{a}$, far, hijo de 'Abd al-Raḥmān -ique Allāh tenga piedad de él!- establecer esta comunicación hacia su oratorio (...)" (cfr. Arjona 1982, 140) ${ }^{15}$.

Entre los autores árabes, quien nos da una visión más completa del sābāt es al-Idrīsī, que en el s. XII describió: "a la derecha del mihrab, entre los dos muros de la Mezquita Alhama, hay una puerta que abre al alcázar por un pasadizo contiguo. Este pasadizo se halla cerrado con ocho puertas de las cuales cuatro se cierran del lado del alcázar y cuatro del lado de la Mezquita Alhama” ( $c f r$. Nieto 1998: 255 - 259).

También al-Maqqari (1591-1632) recoge un texto de Ibn Said quien, citando a su vez a Ibn Baskuwal (+1183), afirma: "Ninguna puerta se ve sobre el muro sur salvo una, al interior de la maqșūra, construida sobre la qibla que conduce al sābāt que enlaza con el

${ }^{14}$ L. Golvin recogió el testimonio oral de Rafael Castejón quien, al parecer pudo intuir los pilares del sābāṭ califal en el transcurso de unas obras en la c/ Torrijos. Tal hallazgo no fue motivo de un estudio del monumento y prácticamente pasó desapercibido (Golvin 1979, nota 116).

${ }^{15} \mathrm{M}$. Ocaña tradujo estas inscripciones ubicadas en las bandas laterales de las portadas y aquilató la fecha de las mismas (Lévi-Provençal 1931: 17-18; Ocaña 1976: 48-51). alcázar de los califas. Por este pasadizo el soberano pasaba desde el alcázar a la mezquita para la oración pública” ( $c f r$. Nieto, ibidem).

Cuatro siglos más tarde Ambrosio de Morales (1577) describió un edificio especialmente sólido, atravesado de arcos fuertes y espesos cubiertos con bóvedas: "Cada arco vazío estaba entre dos cerrados de pared, con una entrada en medio cerrada de puertas de hierro y bronze. Así quedan formadas ocho piezas, cada una con un arco por medio, y ventana grande hacia el río que son las ventanas que ya diximos en la descripción desta primera pared" (Morales 1577: 124).

Contamos con documentos gráficos que muestran el aspecto del sābāt en la última etapa de su existencia. Su presencia se intuye, más que se ve, en la más antigua, un sello de la ciudad de 1360 (González 1945: 356; Caro 1954: 150). Su puerta central podría ser la que aparece a modo de arco de herradura
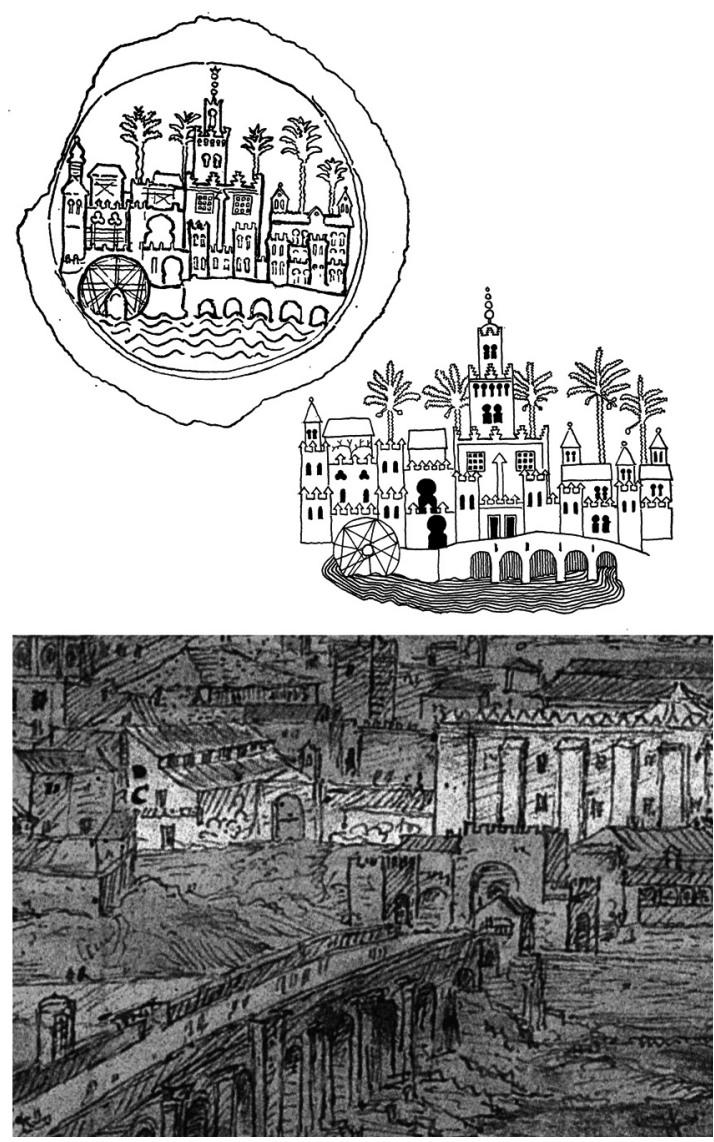

Figura 7. Dos vistas de Córdoba desde la orilla izquierda del río. Arriba, reproducción y esquematización del sello concejil de Córdoba de 1360, según J. Caro Baroja (1954: Fig. 19). Abajo, detalle de alcázar, sābāt y Mezquita - Catedral en el grabado de A. de Wyngaerde (1567). 


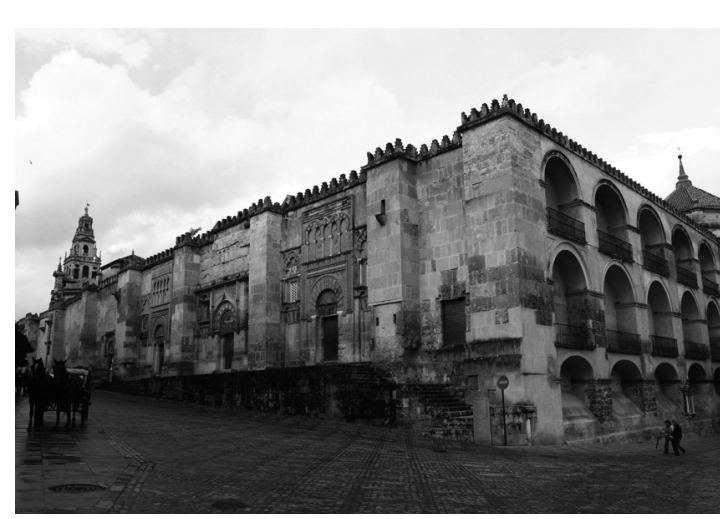

Figura 8. Vista actual del ángulo suroeste de la mezquita de Córdoba, donde se ve la puerta de entrada al sābāt.

muy esquematizado inmediatamente a la izquierda de la mezquita, por encima del edificio. El grabado de Antonio Van den Wyngaerde (1567), muy detallado, se ajusta más a la descripción del pasadizo que hizo Ambrosio de Morales, contemporáneo suyo: aquí el pasadizo se presenta como un edificio abierto a la calle por un solo arco, el que Morales vio "vazío" y cerrado con puertas de hierro y bronce; no representó los arcos laterales que lo flanqueaban porque estaban tapiados, o lo que es lo mismo, "cerrados de pared". Por otra parte, el grabado muestra que en ese momento el $s \bar{a} b \bar{a} t$ califal se cubría con una techumbre de teja a dos aguas cuya altura era inferior a la de la antigua mezquita (Fig. 7).

En cuanto a su distribución interna, al-Idrīsī y Morales afirmaron que el sābāt tenía ocho puertas, de las cuales, cuatro separaban cinco estancias, las que existen en la trasqibla de la aljama. Otra puerta más es visible desde el exterior del edificio, en el ángulo suroeste de la mezquita, la cual, por quedar oculta, no estaba decorada (Fig. 8, 9 y 10). El pasadizo elevado sobre la calle, por tanto, sólo pudo tener tres puertas más ${ }^{16}$, ocho vanos con un peculiar sistema de apertura descrito por ambos autores: "las cuatro primeras de hacia el alcaçar se cierran hacia el, que esta al poniente: y el portero, a lo que parece, venia delante todo el acompañamiento del Rey, abriéndolas, y echandolas hacia el oriente. Las otras quatro se cierran diversamente dos hacia oriente, y otras dos hacia poniente. Y así era menester estuviessen dos otros porteros alli encerrados para abrir" (Morales 1577: 124) ${ }^{17}$.

El califa, en su camino, atravesaba todas las estancias descritas y, llegado al final del recorrido, ya en el interior de la mezquita, accedía a la maqșūra a través de la magnífica puerta situada al oeste del mihrab. Hay que tener en cuenta, no obstante, que el espacio generado

\footnotetext{
${ }^{16}$ Todos los testimonios y propuestas científicas sobre el sābāt están recogidas por M. Nieto en su monografía. Aquí indica las medidas de las estancias del pasadizo que se conservan en el interior de la mezquita. Según Nieto, cada habitación tiene $4,46 \mathrm{~m}$ de largo y la anchura de cada una es la de las naves de la sala de oración con la que está alineada (Nieto 1998: 257). Posteriormente, A. Vallejo ha confirmado que las dimensiones internas del pasadizo de al-Zahrā' $(4,50 \mathrm{~m})$ así como la anchura de su de trasqibla $(1,52 \mathrm{~m})$ son similares a las de la aljama cordobesa (Vallejo 2010: 200).

${ }^{17}$ Sobre este sistema de cierre y su uso en Madinat al-Zahrā', véase la obra de M. Gómez Moreno (1951: 140). Existen varios estudios centrados en las puertas con doble sistema de apertura. B. Pavón Maldonado atribuyó su invención a 'Abd al-Raḥmān III basándose en la crónica anónima de su mandato: "A propósito de ello nos viene bien la Crónica anónima de 'Abd al-Raḥmān III en la que leemos "al-Nasir mandó construir en las puertas de la medina de Córdoba puertas interiores correspondiéndose o correspondientes con las exteriores que se encargaban de defender los porteros. Es caso que no se había hecho antes y que fue una excelente innovación". Pavón puntualizó que "nunca se sabrá si el texto de la Crónica Anónima aludiría a puertas dobles de ingreso o a puertas dobles de ingreso en codo". Según el mismo autor este esquema arquitectónico se debe a la invención de la puerta de cuatro mochetas, ideada para "acotar espacios sucesivos y abovedados de puertas con interiores complejos". Basándose en la crónica anónima, en época de al-Nasir (Pavón 1987: 369).

Un artículo más reciente relaciona este tipo de puerta con las murallas de Córdoba (Escudero et alii 1999).
}

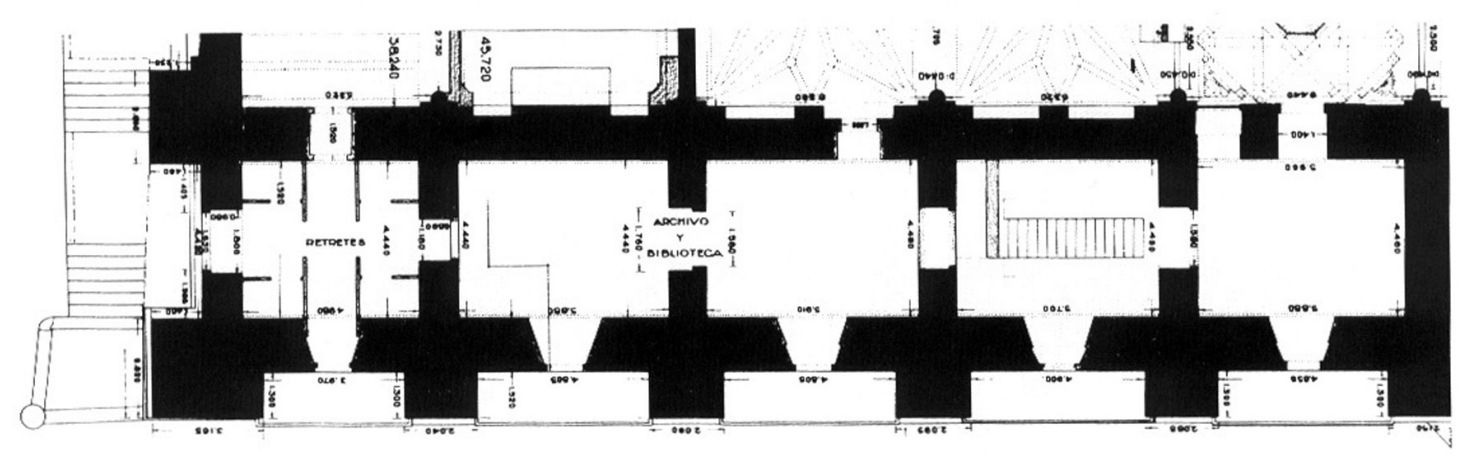

Figura. 9. Planta de la parte del sābāt califal conservada hoy día en el interior del edificio. Se ha girado la imagen para orientarla hacia el norte (Tomado de Nieto 1998: 256). 


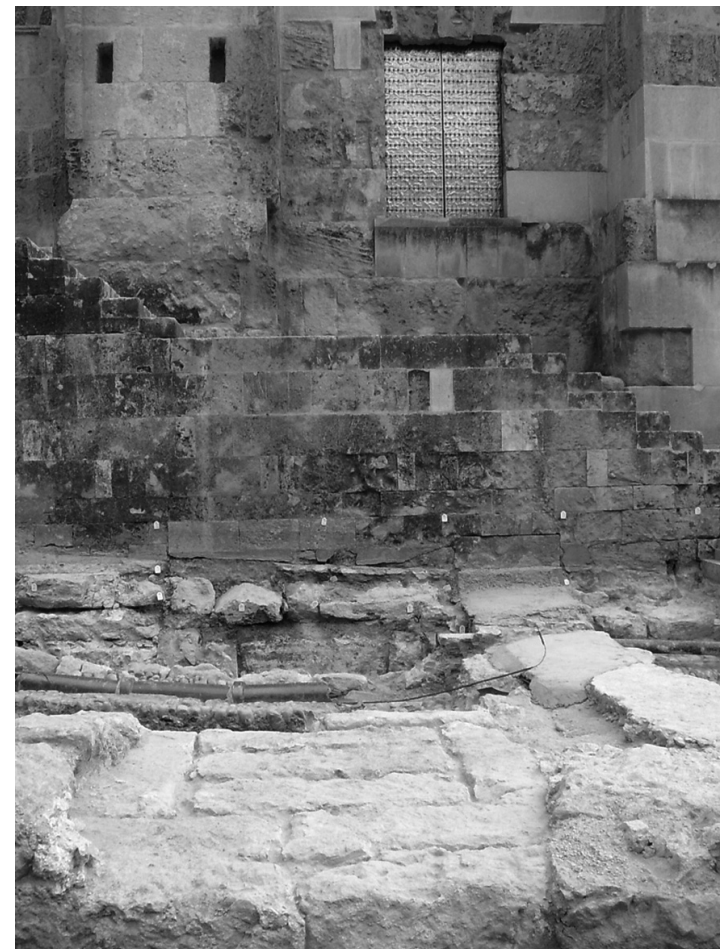

Figura 10. Detalle de la puerta del sābāt califal durante el proceso de excavación del pilar oriental.

entre qibla y trasqibla está dividido en dos pisos, y el superior cuenta con un mayor número de estancias que el inferior, once en total: "se distribuye en tantos compartimentos cuantas son las naves (de la sala de oración), con bóvedas esquifadas, puertas de comunicación y sendas ventanas, hacia el exterior y hacia la mezquita, de las que una conserva una celosía de mármol, muy sutil y con labor de lazo" (Gómez Moreno 1951: 139-140).

Por otra parte, al este del mihrab, la doble qibla de la mezquita daba lugar a un corredor simétrico al propio $s \bar{a} b \bar{a} t$, un espacio que albergaba la sala del tesoro y otras oficinas del templo. La portada por la que se entraba en este espacio gemelo al sābāt, abierta a la calle, sí estaba profusamente decorada ${ }^{18}$. Más tarde, tras la ampliación de Almanzor, quedó integrada dentro de la sala de oración.

Como ya hemos adelantado, el hallazgo de dos pilares del pasadizo de al-Hakam II en la calle Torrijos ha confirmado el testimonio de al-Idrīsī y Morales: al exterior de la mezquita el sābāt se alzaba sobre tres arcos, tal y como ocurría en al-Zahrā' (Fig. 11 y 12$)^{19}$. Habría una estancia sobre cada uno de

\footnotetext{
${ }^{18}$ Sobre la decoración de sendas portadas (Gómez Moreno 1951: 150; Nieto 1998: 231 - 235).

${ }^{19} \mathrm{La}$ reconstrucción del pasadizo realizada por Golvin, basada en el mismo pasaje, planteaba una estructura sostenida sobre cinco arcos (Golvin 1979: 65 y 66). Sobre la simbología del esquema tripartito de las puertas islámicas ver la obra de F. Juez 2003.
}

ellos, tres en total que, sumadas a las cinco que se conservan al interior de la mezquita completarían el número de ocho habitáculos con las que en total contaba el pasadizo. La parte del sābāt ubicada sobre la calle medía casi $25 \mathrm{~m}$ de longitud ${ }^{20}$. Cada uno de los pilares que sostenían el pasadizo, unos $3,10 \mathrm{~m}$ de anchura y $6,55 \mathrm{~m}^{\mathrm{de}}$ longitud ${ }^{21}$. El arco central, correspondiente al espacio entre los dos pilares documentados por nosotros, tenía una anchura de 3,54 m. Más difícil es dilucidar la anchura de los arcos laterales, que hemos calculado, como mínimo, en 2,60 m: esta es la distancia que media entre el pilar oriental y los que podrían ser los restos del pilar anexo a la fachada de la mezquita, oculto bajo el andén que rodea la sala de oración ${ }^{22}$ (Figs. 13 y 14). En el pilar oriental, el mejor conservado, podemos apreciar

\footnotetext{
${ }^{20} \mathrm{El}$ ensanchamiento de la calle hacia el S obligaría a que la fachada meridional del edificio fuera ligeramente más estrecha que la septentrional.

${ }^{21}$ Nótese que los laterales de los dos pilares estaban cercenados por zanjas contemporáneas.

${ }^{22}$ Debió existir un pilar más ubicado junto a la antigua fachada del alcázar, al O de los excavados. Este no fue documentado por no estar afectada dicho extremo de la calle por las obras abordadas en 2007.
}
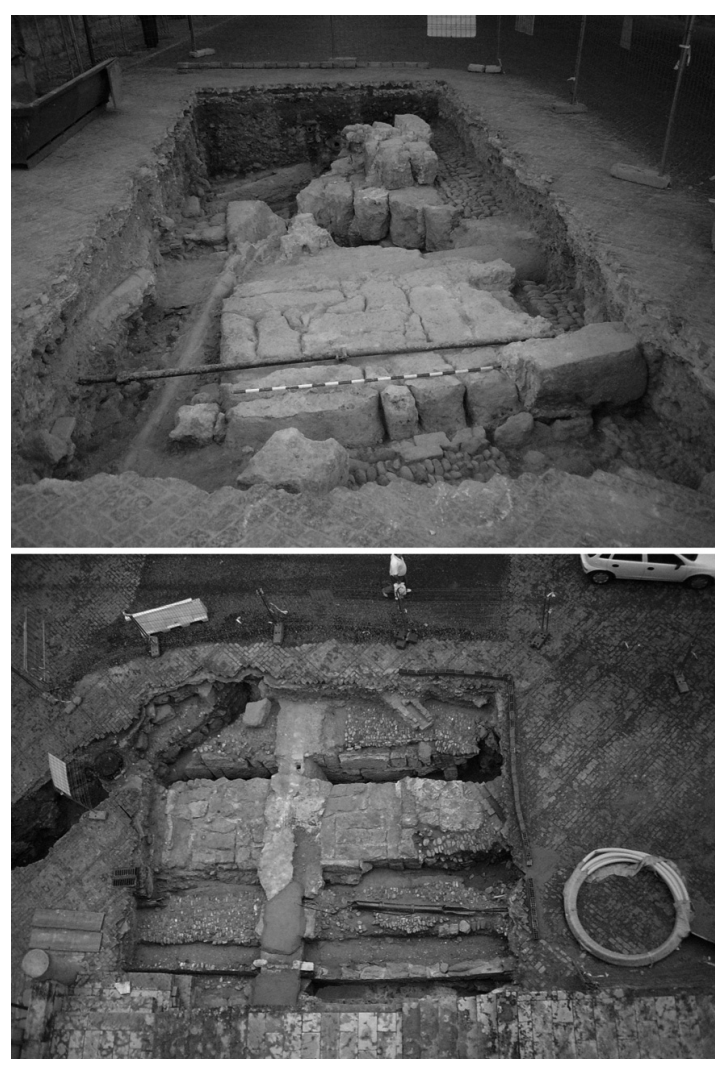

Figura 11. Vista cenital de los dos pilares del sābāt califal durante su excavación. Arriba, pilar occidental; abajo, el oriental. 


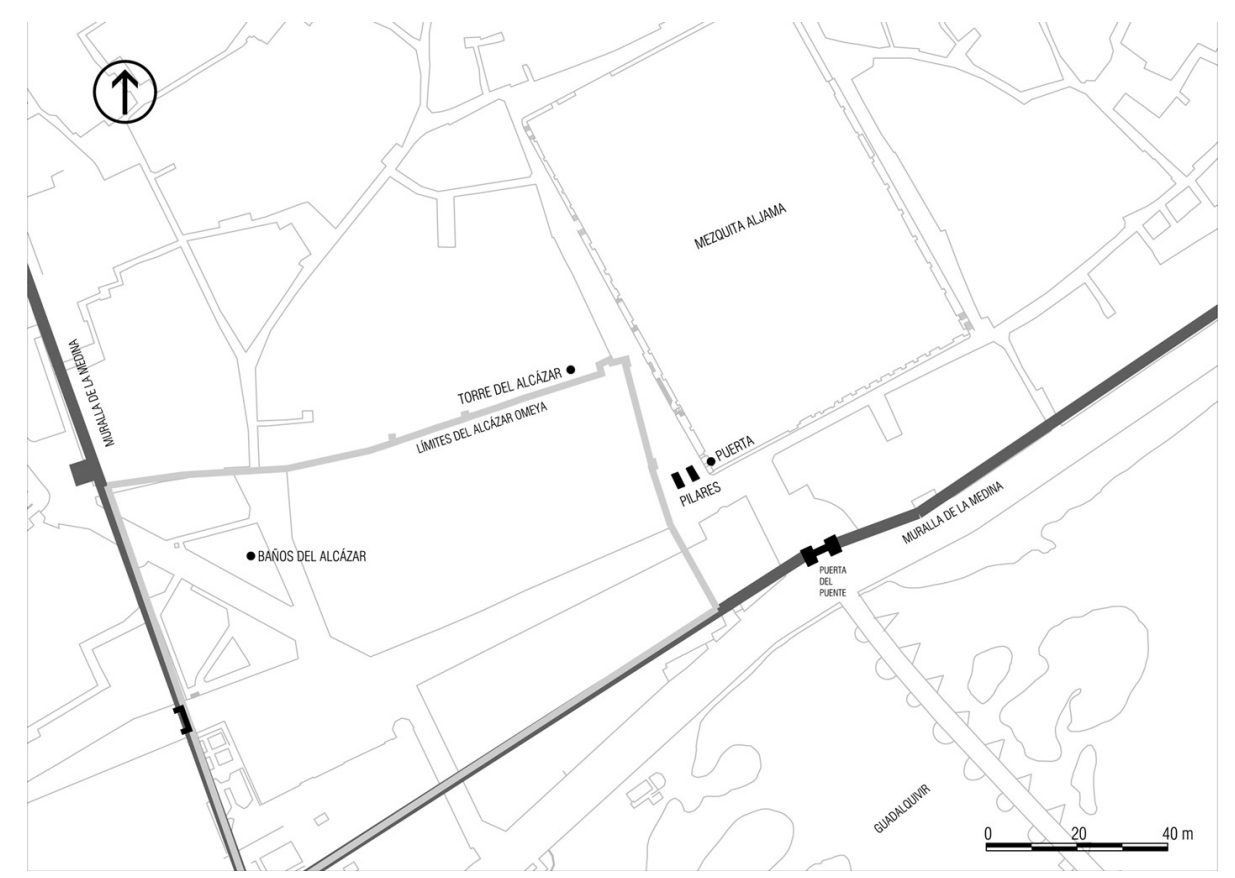

Figura 12. El sābāt califal. Situación del pasadizo respecto al alcázar y la mezquita de Córdoba.

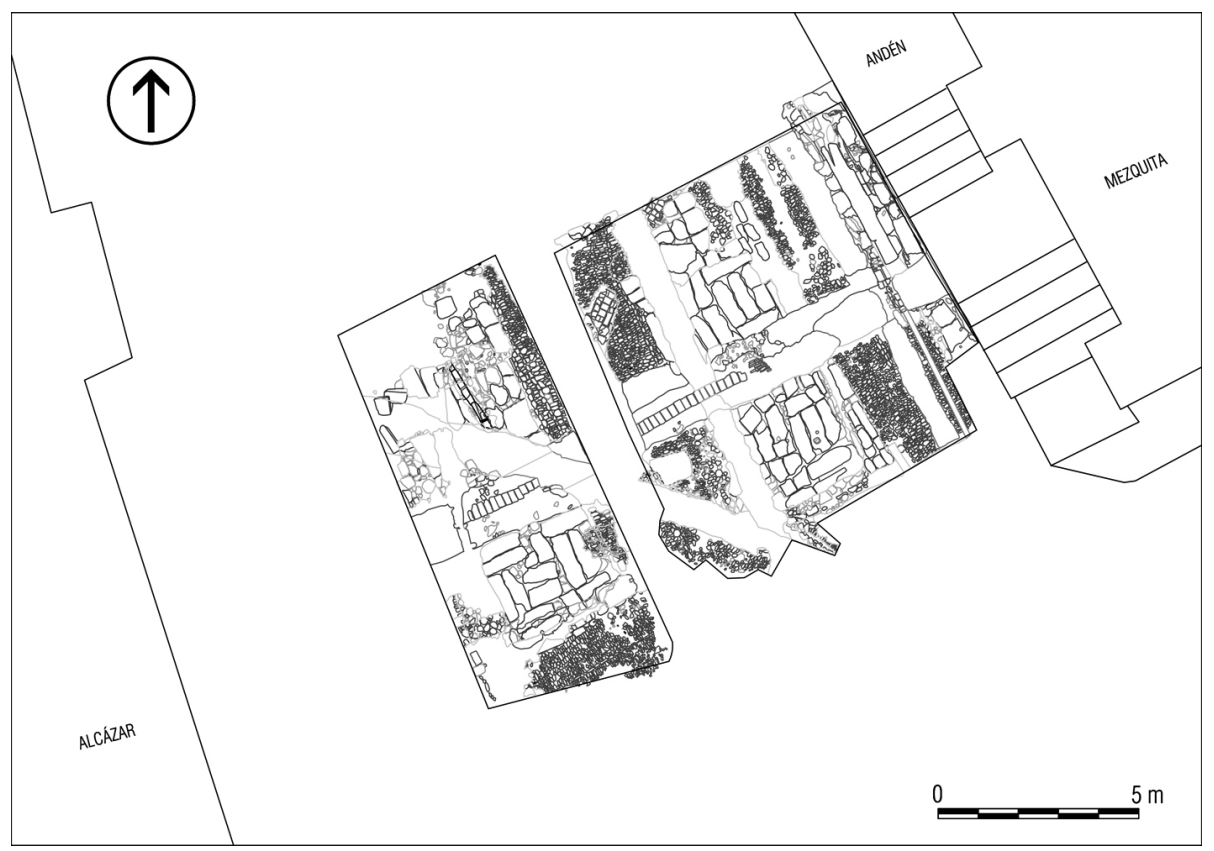

Figura 13. Planta de los cortes estratigráficos en que se hallaron los cimientos del sābāt califal.

el despiece de los sillares de calcarenita: estos se disponen en parejas de sogas y tizones que rodean un machón central, un núcleo pétreo compuesto por tres tizones. El mismo esquema se repite tres veces, mediante la yuxtaposición de tres módulos idénticos, hasta completar la longitud total de la estructura.
Todos los soportes del sābāt se apoyaban sobre una potente cimentación hecha de sillares de mayor tamaño que los de su alzado, la cual superaba los dos metros de profundidad $^{23}$ (Fig. 15). Dicha cimentación, posiblemente

${ }^{23}$ La cimentación del sābāṭ se documentó a través de una 


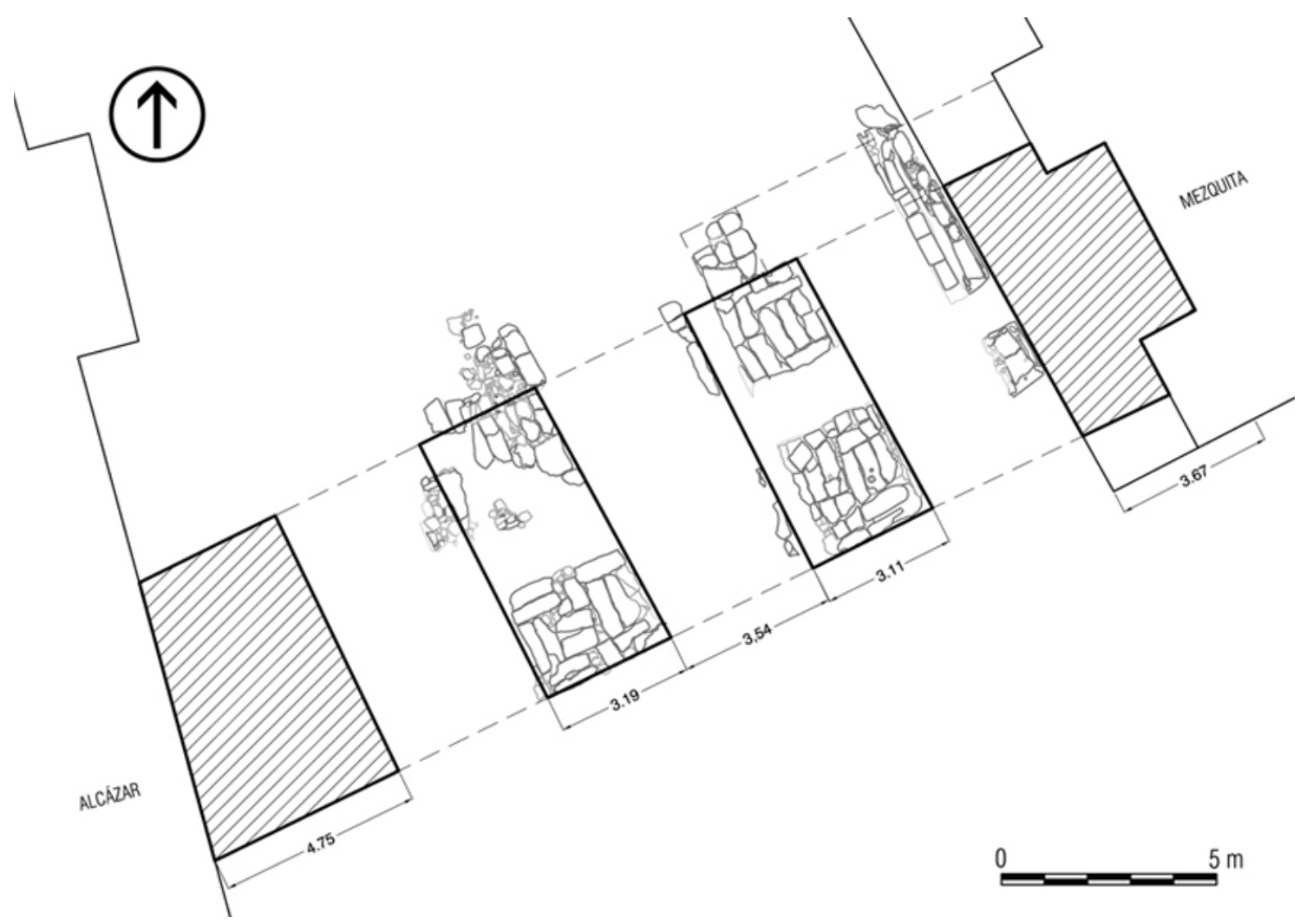

Figura 14. Cimientos de los pilares del sābāt califal con indicación de sus dimensiones.

corrida, quedó oculta por el pavimento de la vía islámica, de la que apenas queda un pequeño tramo bajo el arco occidental del pasadizo (Fig. 16). Es lógico que la Calle Mayor de la capital del califato, mahaŷa ,uẓmà, como la denominan las fuentes, estuviera dignificada con un suelo hecho de grandes losas de materiales resistentes, de acuerdo con la grandiosidad del área urbana por la que transcurría (García Gómez 1965: 361).

Como ya hemos dicho antes, la puerta por la que se accedía desde el pasadizo hasta el corredor posterior a la ampliación de al-Hakam II es visible actualmente sobre la calle. Su dintel a la misma altura que el resto de las puertas de la aljama. Ahora bien, recientes investigaciones han sacado a la luz antiguas fotografías de la fachada occidental del templo que podrían cambiar la imagen que se ha tenido hasta ahora del sābāt. Estas instantáneas, algunas realizadas por F. Hernández, muestran que existía un vano más, actualmente tapiado, sobre la puerta de acceso conservada hoy en día (Fig. 17) (Fernández 2009a: 259). El dato no deja de sorprendernos: ni las fuentes escritas ni los investigadores que nos ha

zanja de alcantarillado de la c/ Torrijos que había atravesado la estructura. precedido contemplaban la posibilidad de un sābāt de dos pisos, y ello a pesar de que examinaron el edificio antes de la restauración de dicho testero. Ambrosio de Morales no hizo ninguna mención al respecto, mientras que el grabado de Wyngaerde, con sus limitaciones, apenas permite plantear un acceso descubierto, una terraza transitable que coronaría el pasadizo conectando con la puerta más alta. Fuera o no útil para el paso de la amplia comitiva que acompañaba al califa, la existencia de un segundo piso implicaría cierta debilidad en un edificio que se pretendía inexpugnable. Si consideramos un sābāt de dos pisos su altura sería, al menos, la misma que la de los muros del alcázar, unos $13 \mathrm{~m}^{24}$, aunque los muros de la mezquita son ligeramente más altos, pues se alzan $16 \mathrm{~m}$ sobre los pavimentos excavados por nosotros ${ }^{25}$. Por otra parte, los arcos del pasadizo, abiertos sobre la calle, no se elevarían más de $6 \mathrm{~m}^{26}$ :

\footnotetext{
${ }^{24}$ Desde la cota de suelo en este punto, 100,60 m.s.n.m. hasta la parte más alta conservada del alcázar, a 113,84 m.s.n.m.

25 Desde la cota de suelo en este punto 100,14 m.s.n.m. hasta la cota 116,11 m.s.n.m., la del coronamiento de la antigua mezquita. De los datos obtenidos en la intervención se deduce una ligera inclinación de los pavimentos de la calle hacia el Sureste (Vide la nota previa).

${ }^{26}$ Se trata de la distancia entre la cota del pavimento de la
} 

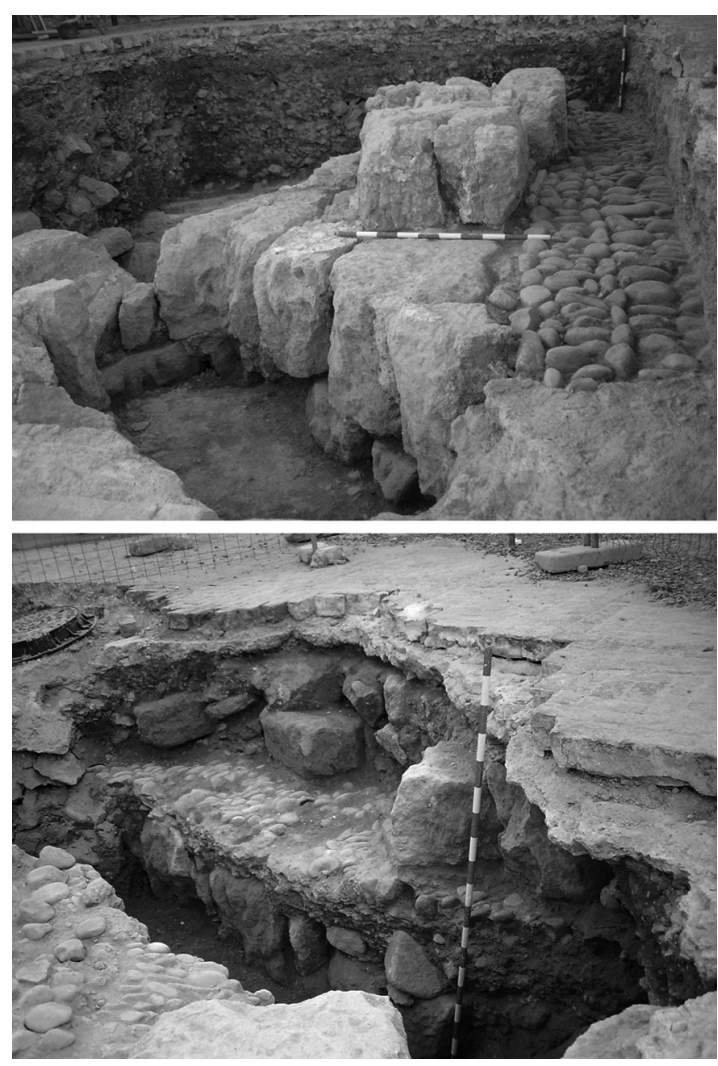

Figura 15. Arriba, vista en alzado del pilar occidental del sābāt en que se aprecia la superposición de la estructura que le sirve de cimentación. Cimentación del pilar oriental debajo de los empedrados de 1609

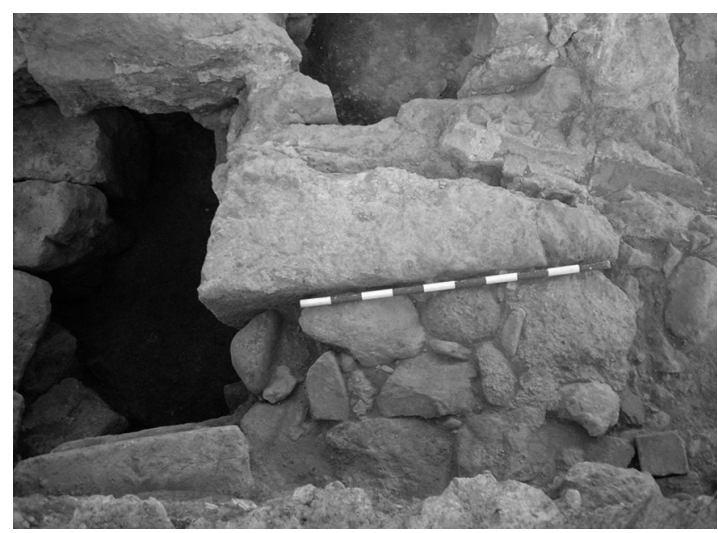

Figura 16. Pavimento de la vía que discurría bajo el arco occidental del sābāt califal.

el conjunto, en cualquier caso, tendría un aspecto realmente macizo (Fig. 18).

Un dato más sobre el aspecto que debió presentar el edificio se desprende del hallazgo de un

calle, 100,60 m.s.n.m. y el umbral de la puerta más baja, de 105,19 m.s.n.m.

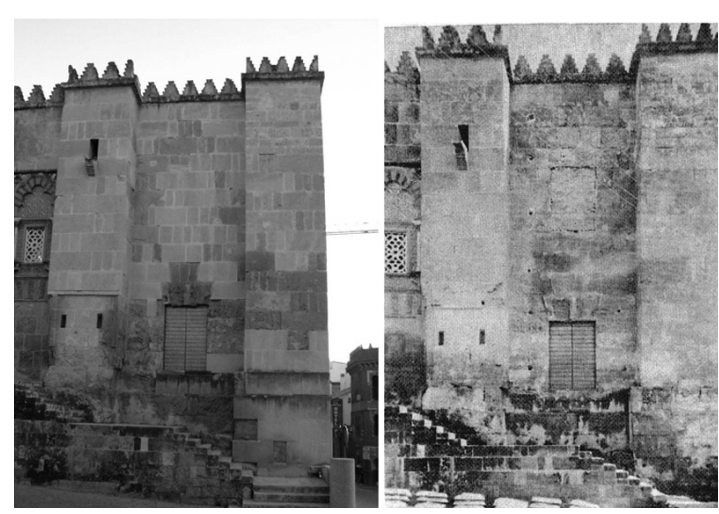

Figura 17. Ángulo suroeste de la mezquita. A la derecha, fotografía previa a su restauración realizada por F. Hernández. Obsérvese la huella de un vano a la altura del segundo piso del sābāt (reproducida en Fernández 2009: 259).
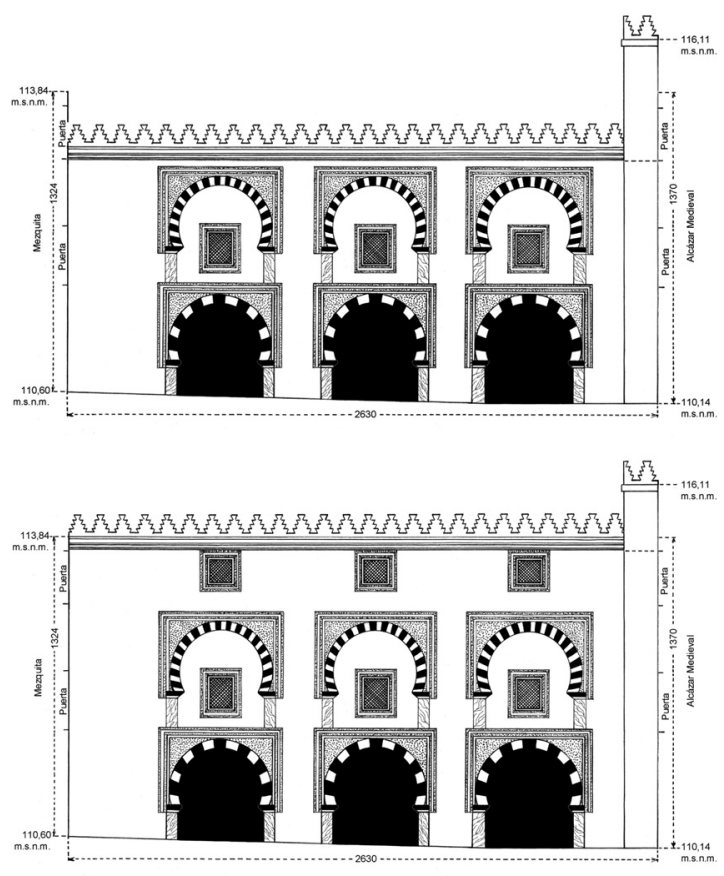

Figura 18. El sābāt califal. Reconstrucción en alzado realizada por J. A. Ortega a partir de los datos de la intervención. Hipótesis con uno y dos pisos de altura.

merlón espigado entre los sillares del derrumbe del sābāt. Este ejemplar, similar a los que rematan la ampliación de al-Hakam II, presenta decoración en relieve en una de sus caras, una especie de estrella de ocho puntas ${ }^{27}$. La pieza pudo coronar el pasadizo

\footnotetext{
${ }^{27}$ Recordemos, no obstante, que en el grabado de Wyngaerde tanto el pasadizo como el alcázar aparecen techados con una cubierta de tejas a dos aguas, y que en sus coronamientos no se representaron merlones.

La pieza apareció en buen estado de conservación: en sus laterales existen restos de enlucido bastante fino, aplicado de
} 
elevado o la fachada oriental del alcázar omeya, igualmente derribada a inicios del s. XVII (Fig. 19), igual que dos fragmentos de columnillas de caliza que aparecieron descontextualizadas durante la excavación ${ }^{28}$ (Fig. 20).

\section{TRANSFORMACIONES TARDÍAS Y REPERCU- SIONES DEL MODELO.}

A lo largo del texto ya hemos adelantado algunas funciones, avatares y transformaciones sufridas por el sābāt califal a lo largo de la Historia. Como dijimos más arriba, desconocemos cómo era su cubierta: de tratarse de una terraza, el califa podría mostrarse a los fieles desde aquí para recibir su aclamación, igual que ocurría Madīnat al-Zahrā. En cualquier caso el pasadizo de Córdoba, como el de la ciudad palatina, fue lugar de encuentro con importantes dignatarios (Vallejo: 2010: 202 y nota 85) y el uso de un acceso protegido entre ambos edificios fue especialmente útil en los episodios que siguieron a la fitna. Ibn 'I ̣̂ārī describe cómo Hišām III, último califa omeya, pasó la última noche de su mandato el 30 de Noviembre de 1031 refugiado en el interior del sābāt: "Bajó Hissam al pasadizo de la aljama, conducente a la maqșūra, con quienes se le unieron de sus hijos y mujeres, (...). Permaneció en ese sitio el resto de aquel día y aquella noche prisionero, sumiso, despreciado, temeroso y fija la vista hacia donde le podía abordar la muerte (...) Aumentó su preocupación y pidió una lámpara para entretenerse a su luz con sus mujeres. Hacía llorar al que le hablaba, considerando las vicisitudes de su suerte" (Ibn 'Iḍārī 1993: 131).

El sābāt siguió en pie después de la Conquista Cristiana y pudo servir de marco arquitectónico a episodios históricos posteriores. Ramírez de las Casas Deza ilustró el asedio a Córdoba por parte de Pedro I el Cruel (1367) en un escenario no exento de fantasía donde el pasadizo vuelve a estar presente. Según el autor, las tropas comandadas por D. Alonso Fernández de Córdoba salieron a defender la ciudad en la que posteriormente fue conocida como Batalla del Campo de la Verdad por la calle del Palacio Episcopal: "al tiempo de atravesar los arcos del pasadizo que de la Catedral iba al Palacio su madre Doña Aldonza de Haro, que estaba en una ventana de aquel le dijo a Don Alonso: Me dicen hijo, que salís a entregar la

forma cuidada. Sobre la cara decorada, en cambio, vimos restos de cal vertida groseramente sobre el relieve, quizás para ocultarlo. Sobre la tipología de merlones islámicos, ver Pavón 1967 y 1969.

${ }^{28}$ Aparecieron en el interior de una cloaca que cortaba la cimentación del pilar occidental y formando parte del derrumbe del sābāt, respectivamente.

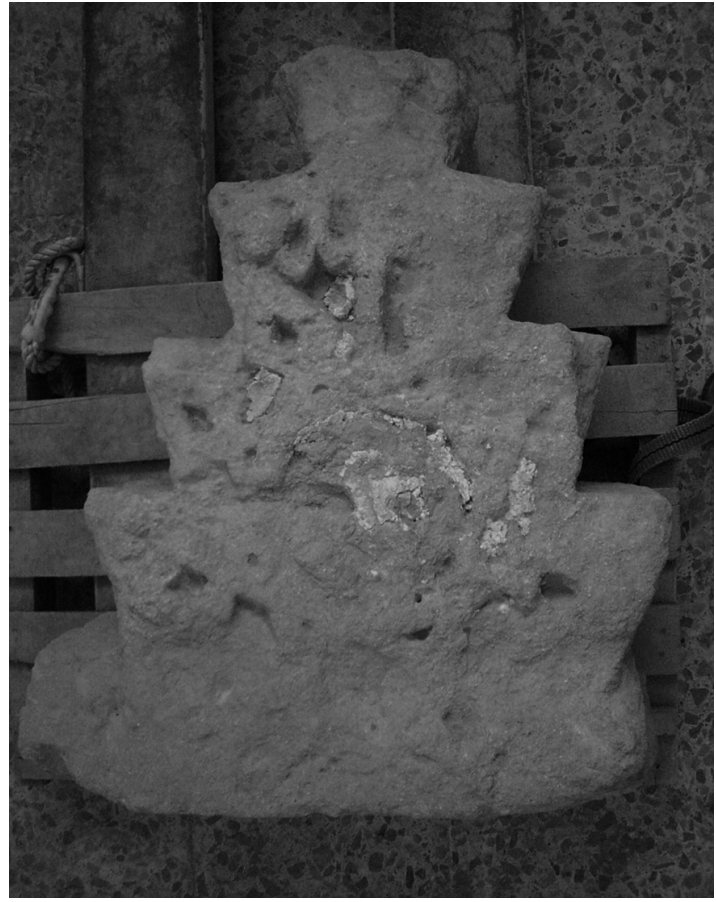

Figura 19. Merlón hallado en el derrumbe del pilar occidental (Medidas: 0,74 x 0,57 x 0,28 m).
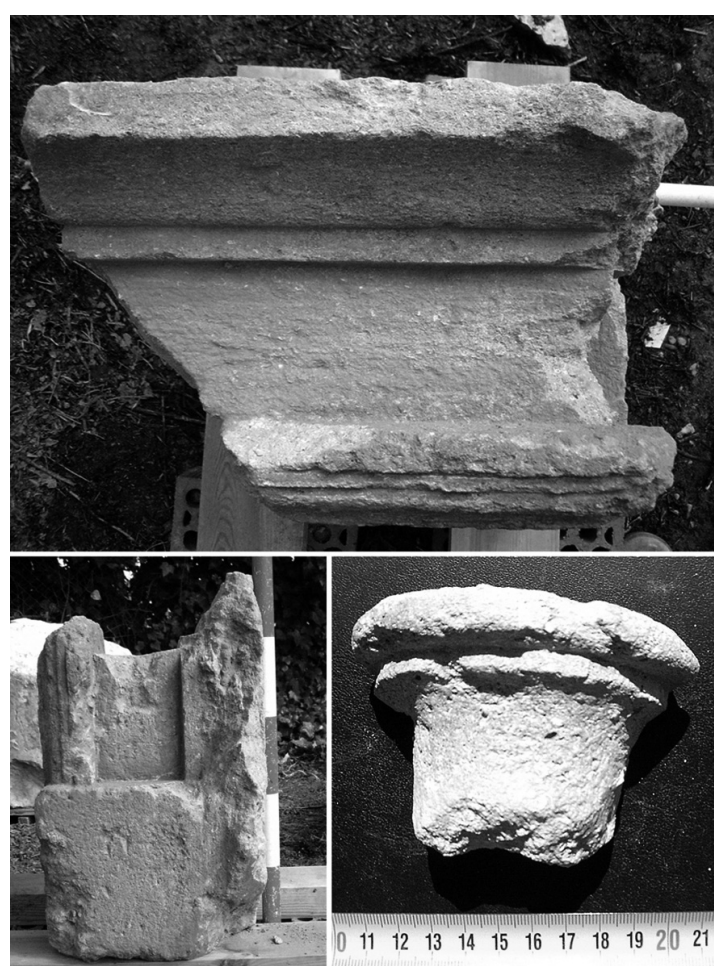

Figura 20. Detalles del frontal y lateral del podium recuperado del derrumbe del pilar oriental. Columnilla fragmentada aparecida en la excavación del corte occidental. 
ciudad a nuestros enemigos (...)" (Ramírez de las Casas 1948, 48 ${ }^{29}$.

El propio Felipe II Pudo hacer uso del sābāt durante su visita a Córdoba en 1570: "preparóse para aposento del rey el palacio del obispo (...) y para que S. M. pudiera ir desde el templo á su palacio sin que le importunase el gentío, se engalanó como era regular el pasadizo por donde los reyes árabes se trasladaban de uno a otro edificio" (Madrazo 1855: 312-313).

Contamos además con otros documentos, estos manuscritos de carácter administrativo, que informan de los avatares que sufrió el edificio en la Edad Moderna. Las cuentas de la Fábrica de la Catedral (1581) estudiadas por M. Nieto, se refieren a la renta de dos casas conservadas bajo los arcos del pasadizo. El asiento de la primera se titula "Casas al pasadizo de la Iglesia" y dice "Tiene más otras casas devaxo del pasadizo frontero del alhorí del pan desta Fábrica que la tiene a renta de por tiempo Catalina Hernández, lavandera" [...]. El asiento de la segunda se titula "Casas que confinan con las de arriba" y en él se dice "Tiene más otras casas que confinan con las de arriba que las tiene a renta e por tiempo Mari Blanca, lavandera” [...] (Nieto 1998: 256). Los textos vuelven a confirmar el cierre de los arcos laterales del pasadizo, referida por Morales e intuida tanto en el sello de Córdoba como en el grabado de Wyngaerde. Una vez tapiados los dos vanos, quizás antes de la Conquista Cristiana, se crearon estancias y viviendas en su interior que el cabildo arrendaba; éstas formarían parte de construcciones adosadas a las fachadas de la antigua mezquita y alcázar, reconvertidos en Catedral y "Casas del Obispo" (palacio episcopal), respectivamente. Sin embargo, los resultados de la excavación no confirman tales modificaciones de forma contundente. Las reformas del sābāt posteriores al siglo $\mathrm{X}$ pudieron consistir en la prolongación de sus pilares hacia el Noroeste, pues aparecieron sendos salientes de sillares adosadas a la cara norte de ambos. No hemos hallado ningún tipo de cerramiento bajo los arcos laterales y en cuanto a la existencia de puertas, solo se documentó una quicialera de piedra de mina, bastante desgastada bajo el arco central, en una posición algo descentrada respecto al pilar occidental (Fig. 21).

La imagen que ofrecía la calle Torrijos en la Edad Moderna, por tanto, era muy distinta a la que presentara en época islámica. Mucho más estrecha de lo que lo había sido en origen, en 1609 se renovó su pavimento: la vía se empedró con cantos ordenados en calles, una técnica muy habitual en las construcciones cordobesas (Fig. 13). El documento en el que se recogen las cuen-

\footnotetext{
${ }^{29}$ El mismo episodio lo recoge Ramírez de Arellano (1874: 485).
}

tas de dicha obra se titula "Empedrado de la calle de los Arquillos", señalando que los arcos del pasadizo aún dominaba la imagen de la vía a principios del s. XVII ( $c f r$. Nieto 1998: 256). Otro texto informa sobre el empedrado de la calle situada entre la Mezquita y las "Casas del Obispo en las que se integraba el alhorí" ${ }^{30}$ de donde deducimos que el arco occidental del sābāt albergaba un almacén de grano.

Paradójicamente, la pavimentación de la calle Torrijos apenas fue una década anterior al derribo del sābāṭ. Las cuentas de la Fábrica de la Catedral de los años 1617 y 1620 informan de la destrucción del pasadizo por orden del que entonces era obispo de Córdoba, Fray Diego de Mardones "por razón de la obra nueva que hizo en sus casas obispales" ( $c f r$. Nieto 1998: 256). Los sillares del antiguo pasadizo se reaprovecharían en las construcciones financiadas por el obispo, pero una buena parte de sus materiales quedaron a pie de obra como una colmatación intencionada que sirvió para atenuar la inclinación del acceso a la Puerta del Puente. Entre estas piezas se hallaron el merlón y las columnillas antes comentadas, así como un podio de pequeño tamaño (Fig. 21).

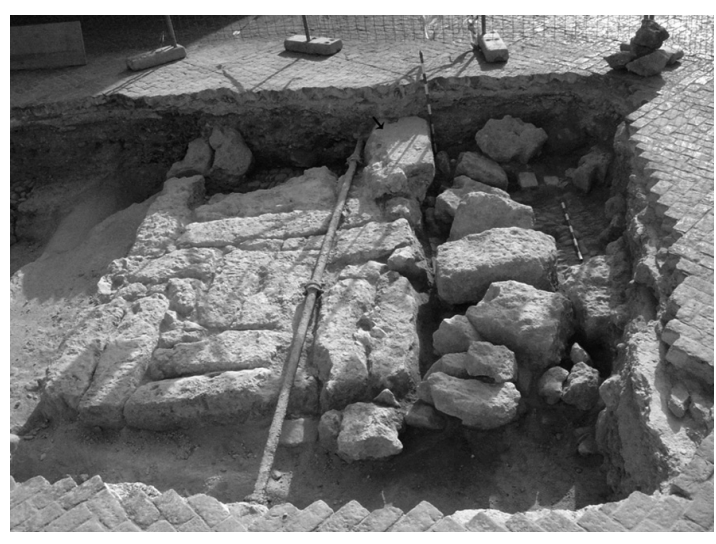

Figura 21. Vista del derrumbe del pasadizo junto al pilar occidental. La flecha al fondo de la imagen señala la ubicación de una quicialera de piedra de mina.

No hay duda de que existe una evolución formal entre el primer $s a \bar{b} a \bar{t} t$ cordobés, el de 'Abd Allāh, y el construido por al-Hakam II, que supuso la consolidación de una tipología arquitectónica. Siglos después, se daría un paso más con la construcción de un nuevo pasadizo tras la aljama de la capital almohade, Sevilla ${ }^{31}$ :

\footnotetext{
${ }^{30}$ Almacén de cereales de la Fábrica procedente de los diezmos.

${ }^{31}$ Volvemos a recordar una vez más en este punto el pasaje del Muqtabis en el que Ibn Hayyan indica que aunque "AbdAllāh fue el primero de los califas Umayya que en Andalucía adoptó esa costumbre. Todos los que sucedieron imitaron su ejemplo" (vide supra).
} 
la comparación entre los sābāțāt de Qurțuba con el sevillano, de finales del siglo XII, demuestra que el modelo cordobés no lo fue tanto en lo formal o técnico como en lo conceptual e ideológico. En palabras de los investigadores que la han estudiado, "la fábrica de la mezquita de Sevilla se adecuó a la de la muralla preexistente de tal manera ambas quedarían conformadas como una única estructura" 32 (Tabales et alii 2002: 135). Efectivamente, el sābāt sevillano también fue un espacio de tránsito adecuado para que el califa acudiese a la oración del viernes sin ser visto por sus súbditos. Sin embargo, en ese caso la topografía del terreno obligó a construirlo con un primer tramo elevado y un tramo final semisoterrado, a modo de criptopórtico, que se encajaba entre la muralla de la ciudad y la cabecera de su aljama. Así, el último sābāt andalusí formó parte del diseño urbano del centro del imperio almohade $^{33}$, Sevilla. Igual que en Córdoba, el binomio mezquita - palacio volvió a repetirse y a materializarse en la construcción de un edificio singular cuyos principios ideológicos, pensamos, son los mismos que los cordobeses, es decir, la legitimación de los poderes religioso y político encarnados en el califa ${ }^{34}$.

\section{BIBLIOGRAFÍA}

Arjona Castro, A. 1982: Anales de la Córdoba musulmana (711-1008), Córdoba.

Caro Baroja, J. 1954: "Norias, azudas, aceñas", Revista de dialectología y tradiciones populares 10 (1/2), 29-160.

Castelló Moxó, F. 1976: “Descripción nueva de Córdoba musulmana. Transcripción y notas", Anuario de Filología 2, 123-154.

Cómez Ramos, R. 1988: "Pasadizo o sābāt, un tema recurrente en la arquitectura andaluza", Laboratorio de Arte: Revista del Departamento de Historia del Arte 1, 13-28.

\footnotetext{
${ }^{32}$ La muralla preexistente, almorávide, consiste en una potente estructura de argamasa de tres metros de altura y dos y medio de anchura. A cuatro metros de esta se encuentra el muro de qibla de la mezquita: este espacio que separa la aljama y la muralla servía para albergar el pasadizo, el cual, una vez alcanzado el mihrab, bien podía virar hasta el alcázar o bien continuar paralelo a la qibla hasta la entrada primitiva del Dar al Imara (Tabales et alii 2002: 135).

${ }^{33}$ Existe un paralelismo innegable entre los alminares de las mezquitas de Sevilla y Koutoubia, capital africana del imperio almohade. Sin embargo, no nada indica que ésta última mezquita contara con un sābāṭ que la uniera al palacio del califa (Triki 1986: 22-23; Ewert 1987: 199).

${ }^{34}$ R. Cómez aludió a la transmisión del esquema arquitectónico del sābāṭ a la arquitectura del Barroco con significados simbólicos similares a los que planteamos para época islámica (Cómez 1988).
}

Cressier, P. 1984: "Les chapiteaux de la grande Mosquée de Cordoue (oratoires d"'Abd ar-Rahman I et d'Abd ar-Rahman II) et la sculpture de chapiteaux à l'époque émirale. Première partie", Madrider Mitteilungen 25, 216-281.

Cressier, P. 1985: "Les chapiteaux de la grande Mosquée de Cordoue (oratoires d"'Abd ar-Rahman I et d' Abd ar-Rahman II) et la sculpture de chapiteaux à l'époque émirale. Deuxième partie", Madrider Mitteilungen 26, 257-313.

Epalza Ferrer, M. 1999: "La mezquita, reguladora de espacios urbanizados y templo de la acústica”, F. R. García y F. Acosta (coords.), Córdoba en la Historia: la construcción de la urbe, Córdoba, 97-110.

Escudero, J. M., Morena, J. A., Vallejo, A. y Ventura, A. 1999: "Las murallas de Córdoba (El proceso constructivos de los recintos desde la fundación romana hasta la baja Edad Media)", F. R. García y F. Acosta (coords.), Córdoba en la historia. La construcción de la urbe, Córdoba, 201-224.

Ettinghausen, R. y Grabar, O. (1987): Arte y Arquitectura del Islam (650-1250), Madrid.

Ewert, C. 1987: "Tipología de la mezquita en Occidente: de los Omeyas a los Almohades", Actas del II Congreso de Arqueología Medieval Española, Vol. I, Madrid, 179-204.

Fernández Puertas, A. 2009a: Mezquita de Córdoba: su estudio arqueológico en el siglo XX, Granada.

Fernández Puertas, A. 2009b: "Excavaciones en la mezquita de Córdoba", A. Fernández-Puertas y P. Marinetto Sánchez (eds.), Arte y cultura. Patrimonio hispanomusulmán en al-Andalus, Granada, 9-132.

García Bellido y García de Diego, J. 2000: "Morfogénesis de la ciudad islámica: algunas cuestiones abiertas y ciertas propuestas explicativas", P. Cressier, M. Fierro, y J. P. Van Staevel (coords.), Actas del Coloquio L'urbanisme dans l'Occident musulman au Moyen Âge. Aspects juridiques, Madrid, 243-284.

García Gómez, E. 1965: “Topografía cordobesa en los anales de al Hakam II por 'Isà Razi", al-Andalus XXX, 319-379.

González González, J. 1945: "Los sellos concejiles de España en la Edad Media”, Hispania 15: 339-384.

Golvin, L. 1979: L'art hispano-musulmane, Essai sur l'architecture religieuse musulmane t. 4, Paris.

Gómez Moreno, M. 1951: El arte árabe español hasta los almohades; Arte mozárabe, Ars Hispaniae III, Madrid.

Hernández Álvarez, F. 1975: El alminar de Abd alRaḥmān III en la mezquita mayor de Córdoba. Génesis y Repercusiones, Granada. 
Ibn 'Iḍārī al-Marrakusi 1993: La caída del Califato de Córdoba y los Reyes de Taifas. al-Bayan al-Mugrib, Edición y Traducción. F. Maíllo, Salamanca.

Ibn Hayyan 1951: al Muqtabis III, Edición y Traducción, J. E. Guárieb, Buenos Aires, 106-162.

Juez Juarros, F. 2003: Símbolos de poder en la arquitectura de Al-Andalus, Tesis Doctoral, Universidad Complutense de Madrid.

Kuban, D. 1994: "The central arab lands", The Mosque. History, architectural development and regional diversity, London, 77-100.

Lévi-Provençal, E. 1931: Inscriptions árabes d'Espagne, Paris.

Lévi-Provençal, E. 1950: España musulmana hasta la caída del califato de Córdoba (711-1031), R. Menéndez Pidal (ed.), Historia de España IV, Madrid.

Madrazo, P. 1855: Recuerdos y bellezas de España, Madrid.

Marçais, G. 1929: Manuel d'art musulman. L'architecture: Tunisie, Algérie, Maroc, Espagne, Sicile, t. I: du IX au XII siècle, Paris.

Marfil Ruiz, P. 2003: "Ampliación de la mezquita de Córdoba por Almanzor", A. Torremocha y V. Martínez (ed.), Al-Andalus y el Mediterráneo en torno al año mil: la época de Almanzor, Algeciras, 77-88.

Marfil Ruiz, P. 2010: Las puertas de la mezquita de Córdoba durante el Emirato Omeya, Tesis Doctoral (inédita), Universidad de Córdoba.

Montejo, A., Garriguet, J. A. 1998: "El Alcázar andalusí de Córdoba: estado actual de la cuestión y nuevas hipótesis", Actas del I Congreso Internacional Fortificaciones en Al-Ándalus, Algeciras, 303-332.

Montejo, A., Garriguet, J. A. y Zamorano, A. 1999: "El Alcázar Andalusí de Córdoba y su entorno urbano", F. R. García y F. Acosta (coords.), Córdoba en la Historia. La construcción de la Urbe, Córdoba, 163-172.

Morales, A. 1577: Las Antigüedades de las ciudades de España, Alcalá de Henares.

Nieto Cumplido, M. 1998: La Catedral de Córdoba, Córdoba.

Ocaña Jiménez, M. 1942: "La basílica de San Vicente y la gran mezquita de Córdoba, al-Andalus VII, 347-366.
Ocaña Jiménez, M. 1976: Las inscripciones en mosaico del Mihrab de la Gran Mezquita de Córdoba y la incógnita de su data, Madrider Forschungen 11 , Berlin.

Ocaña Jiménez, M. 1979: "Precisiones sobre la historia de la mezquita de Córdoba. Nuevo examen de los textos", Cuadernos de Estudios Medievales 4-5: 275-282.

Pavón Maldonado, B. 1966: Memoria de la excavación de Madinat al-Zahrā, Madrid.

Pavón Maldonado, B. 1967: Las almenas decorativas hispanomusulmanas, Madrid.

Pavón Maldonado, B. 1969: "Sobre el origen sirio de las almenas decorativas hispanomusulmanas", al-Andalus 34 (1), 201-204.

Pavón Maldonado, B. 1987: "Las puertas de ingreso directo en la arquitectura hispanomusulmana. La superposición arco-dintel de la Puerta de Bisagra de Toledo", al-Qantara 8 (1/2), 347-394.

Peña Jurado, A. 2010: Estudio de la decoración arquitectónica romana y análisis del reaprovechamiento de material en la Mezquita Aljama de Córdoba, Córdoba.

Ramírez de Arellano, T. 1874: Paseos por Córdoba, Córdoba.

Ramírez de las Casas Deza, L. M. 1948: “Anales de la ciudad de Córdoba”, Boletín de la Real Academia de Córdoba 60, 43-50.

Rubiera, M. J. 1988: La arquitectura en la literatura árabe: datos para una estética de placer, Madrid.

Tabales, M. A., Romo, A. S., García, E., y Huarte, R. 2002: "Investigaciones arqueológicas en la acera de levante de la Catedral de Sevilla", Aula Hernán Ruiz (ed.), Magna Hispalensis I. Recuperación de la Aljama Almohade, Sevilla, 115- 168.

Torres Balbás, L. 1965: “Arte califal”, R. Menéndez Pidal, (ed.), Historia de España V, Madrid, 331-788.

Triki, H. 1986: Marrakech, Singapur.

Valdés Fernández, F. 1988: “Arqueología de alAndalus de la conquista árabe a la extinción de las primeras taifas", L. Suárez y V. A. Álvarez (coords.), Historia general de España y América t. III, Madrid, 545-617.

Vallejo Triano, A. 2010: La ciudad califal de Madinat al-Zahrā': arqueología de su excavación, Córdoba.

Recibido: 16-12-2011

Aceptado: 26-06-2012 